\title{
Eurasian Cold Air Outbreaks under Different Arctic Stratospheric Polar Vortex Strengths $\mathscr{O}$
}

\author{
JINLONG HUANG AND WENSHOU TIAN \\ Key Laboratory for Semi-Arid Climate Change, Ministry of Education, College of Atmospheric Sciences, \\ Lanzhou University, Lanzhou, China
}

(Manuscript received 23 September 2018, in final form 17 February 2019)

\begin{abstract}
This study analyzes the differences and similarities of Eurasian cold air outbreaks (CAOs) under the weak (CAOW), strong (CAOS), and neutral (CAON) stratospheric polar vortex states and examines the potential links between the polar vortex and Eurasian CAOs. The results indicate that the colder surface air temperature (SAT) over Europe in the earlier stages of CAOW events is likely because the amplitude of the preexisting negative North Atlantic Oscillation pattern is larger in CAOW events than in CAON and CAOS events. Marked by the considerably negative stratospheric Arctic Oscillation signals entering the troposphere, the SAT at midlatitudes over eastern Eurasia in CAOW events is colder than in CAON events. A larger diabatic heating rate related to a positive sensible heat flux anomaly in CAOW events likely offsets, to some degree, the cooling effect caused by the stronger cold advection and makes the differences in areaaveraged SAT anomalies over northern Eurasia between the CAOW and CAON events look insignificant in most stages. Massive anomalous waves from the low-latitude western Pacific merge over northeastern Eurasia, then weaken the westerly wind over this region to create favorable conditions for southward advection of cold air masses in the earlier stages of all three types of CAOs. This study further analyzes the interannual relationship between the stratospheric polar vortex strength and the intensity of Eurasian CAOs and finds that climate models participating in phase 5 of the Coupled Model Intercomparison Project (CMIP5) relative to the reanalysis dataset tend to underestimate the correlation between them. The relationship between them is strengthening under representative concentration pathway 4.5 (RCP4.5) and $8.5(\mathrm{RCP} 8.5)$ scenarios over the period 2006-60. In addition, the intensity of Eurasian CAOs exhibits a decreasing trend in the past and in the future.
\end{abstract}

\section{Introduction}

As one of the severe weather phenomena over Eurasian continent during winter, cold air outbreaks (CAOs) have drawn a great deal of attention due to their tremendous impacts on residents, agriculture, transportation, etc. (e.g., Zhao et al. 2008; Wen et al. 2009; Zhou et al. 2009; Zhou et al. 2011; Xie et al. 2014). CAOs are often characterized by long-lasting extreme cold air with wide spatial coverage and a better understanding of CAOs occurring over the Eurasian continent is important not only for the scientific community, but also for society as a whole. Although the forecast accuracy in the lead

\footnotetext{
Supplemental information related to this paper is available at the Journals Online website: https://doi.org/10.1175/JAS-D-180285.s1.
}

Corresponding author: Wenshou Tian, wstian@lzu.edu.cn time of Eurasian CAOs has to a large extent been improved (e.g., Cai et al. 2016; Yu et al. 2015a,b,c), it is quite challenging to accurately forecast the intensity, spatial coverage, and duration of Eurasian CAOs because of their highly variable nature. Therefore, it is still worthwhile to examine the critical processes affecting the evolution of Eurasian CAOs.

Various factors affecting the Eurasian CAOs have been reported in previous studies: for example, the Siberian high, the Arctic Oscillation (AO), El Niño-Southern Oscillation (ENSO), and Madden-Julian oscillation (MJO). Ding (1987) pointed out that the strengthened Siberian high corresponds well to an increase in the possibility of East Asian CAOs. Park et al. (2011) found that weaker Siberian high and Aleutian low could lead to shorter duration of East Asian CAOs, and negative AO phase is often accompanied by the large-amplitude and longlasting CAOs. Jeong and Ho (2005) also indicated that CAOs over East Asia in the negative AO phase are more 
frequent than that of neutral and positive AO phases. Song and $\mathrm{Wu}$ (2018) further confirmed that East Asian cold events have different properties between positive and negative AO phases. In addition, ENSO (Zhang et al. 1997; Chen et al. 2004; Ineson and Scaife 2009) and MJO (Jeong et al. 2005; Park et al. 2010) can also affect the properties of Eurasian CAOs through modulating the upper-tropospheric circulation.

Though Eurasian CAOs are predominantly controlled by tropospheric processes, more and more studies have stressed the importance of stratospheric circulation anomalies in the occurrence and evolution of Eurasian CAOs. The stratospheric anomalous signals can exert an important influence on the tropospheric circulation by several proposed mechanisms, that is, by the downward migration of zonal wind anomalies induced by wavemean flow interaction (Plumb and Semeniuk 2003; Lubis et al. 2018b), by the adjustment of tropospheric flow to stratospheric potential vorticity anomalies (Hoskins et al. 1985; Black 2002), by the influence of stratospheric poleward/equatorward mass circulation on surface pressure (Cai and Ren 2007), and by reflecting the upwardpropagating planetary waves (Perlwitz and Harnik 2003; Shaw et al. 2010; Lubis et al. 2016, 2017). Jeong et al. (2006) found that the negative stratospheric potential vorticity anomalies over northern Eurasia by potential vorticity adjustment can lead to anomalous cold surface weather in East Asia. In addition, the anomalous poleward mass circulation in the stratosphere (e.g., Cai and Ren 2007; Cai et al. 2016; Yu et al. 2015a,b, 2018) and the easterly phase of the stratospheric quasi-biennial oscillation (e.g., Thompson et al. 2002) are also reported to be connected with cold surface temperature anomalies over Eurasia.

The stratospheric polar vortex states, in particular, are thought to play a nonnegligible role in Eurasian CAOs (e.g., Kolstad et al. 2010; Wang and Chen 2010; Sigmond et al. 2013; Tomassini et al. 2012; Woo et al. 2015; Nath et al. 2016; Zhang et al. 2016; Hu et al. 2018; Huang et al. 2018). Kolstad et al. (2010) found that the probability of CAOs at mid- and high latitudes in the Northern Hemisphere increases by more than $50 \%$ during the life cycle of the stratospheric weak polar vortex events. Wang and Chen (2010) analyzed the CAOs occurring in December 2009 in the Northern Hemisphere and found that this cold condition can be interpreted in terms of the extremely negative phase of AO at the surface, which is closely related to the anomalously weak stratospheric polar vortex. Kretschmer et al. (2018) further indicated that Eurasian temperatures are anomalously low under the extremely weak stratospheric polar vortex states. Although the statistical link exists between the occurrence of Eurasian CAOs and weak stratospheric polar vortex states, there is no one-to-one correspondence between them (Waugh et al. 2017). This is partly because some weak stratospheric polar vortex events can extend downward into the troposphere and then exert a significant impact on the troposphere while others cannot (Runde et al. 2016; Karpechko et al. 2017; Lubis et al. 2018a; Zhang et al. 2019). In addition, Eurasian CAOs can occur when the stratospheric polar vortex is anomalously strong (e.g., Garfinkel et al. 2017) and also occur in the absence of any perturbations in the stratosphere (e.g., Waugh et al. 2017). Therefore, when studying the relationship between the stratospheric polar vortex and Eurasian CAOs it is crucial to classify Eurasian CAOs based on the stratospheric polar vortex states, since the properties of CAOs are likely different under the different stratospheric polar vortex states.

Most previous studies diagnosed the impacts of stratospheric polar vortex on the troposphere mainly by compositing extreme stratospheric polar vortex events. Given the fact that not all anomalous polar vortex events can exert a significant impact on the troposphere, we classify Eurasian CAOs into three categories based on the stratospheric polar vortex strength in this study for the purpose of diagnosing the differences and similarities of Eurasian CAOs under different vortex states. The underlying mechanisms responsible for the influences of the stratospheric polar vortex on Eurasian CAOs are also discussed. This paper is structured as follows: section 2 describes the data and methodology, sections 3-5 present the main results in this work, and section 6 provides a summary of the main results.

\section{Data and method}

The Japanese 55-year Reanalysis (JRA-55) dataset (Kobayashi et al. 2015) conducted by the Japan Meteorological Agency (JMA) for the period 1958-2017 is used in this study. The geopotential height, air temperature, and horizontal winds at 37 pressure levels from 1000 to $1 \mathrm{hPa}$ have a horizontal resolution of $1.25^{\circ}$ latitude $\times 1.25^{\circ}$ longitude. The surface air temperature (SAT), sea level pressure (SLP), and surface horizontal winds also have a horizontal resolution of $1.25^{\circ}$ latitude $\times$ $1.25^{\circ}$ longitude. The diabatic heating rate, the surface sensible heat net flux, and relevant meteorological fields from the National Centers for Environmental PredictionNational Center for Atmospheric Research (NCEPNCAR) reanalysis dataset (Kalnay et al. 1996) is also analyzed in this study. The analysis period covers 59 winters (December-February) from December 1958 to February 2017. The winter of a specific year in this paper refers to December of the specific year and January and February of the following year. The anomalies presented 
in this study are formed by subtracting the daily climatological annual cycle from the original data at all time steps.

Eurasian wintertime SAT anomalies are defined as the area-weighted $\left(40^{\circ}-65^{\circ} \mathrm{N}, 0^{\circ}-120^{\circ} \mathrm{E}\right)$ average of wintertime surface air temperature anomalies at all land grid points. We define Eurasian CAOs by requiring the area-averaged Eurasian SAT anomaly to be below its overall wintertime 10th percentile $\left(\sim-3.8^{\circ} \mathrm{C}\right)$ for at least 2 consecutive days. To ensure the independence of these cold events, CAOs need to be separated by at least 5 days during which area-averaged SAT anomalies are warmer than the threshold. Based on this approach, 64 Eurasian CAO events are identified during the 1958/59 to 2016/17 winters (DJF). The onset (day 0; see Table S1 in the online supplemental material) of a CAO event is defined as the first day on which Eurasian SAT anomalies dropped below the 10th percentile. In the following, the negative and positive signs refer to days prior to and after the onset, respectively.

To examine the relationship between Eurasian CAOs and the stratospheric polar vortex strength, we classify the Eurasian CAOs into three categories with respect to the stratospheric polar vortex strength. First, according to the method in Baldwin and Dunkerton (2001), we calculate the northern annular mode (NAM) index, which is further normalized and vertically averaged from 150 to $10 \mathrm{hPa}$, to evaluate the strength of the polar vortex in the lower to middle stratosphere. Second, the vertically averaged NAM index is temporally averaged over -7 to +7 days relative to the onset date of CAOs. The 15-day average ensures that the NAM signals related to anomalously strong or weak stratospheric polar vortex have enough time to approach the troposphere (Huang et al. 2017). A strong or weak polar vortex state in the lower to middle stratosphere is recognized when the calculated NAM index is greater than 0.7 or less than -0.7 , respectively. The choice of 0.7 standard deviations represents a reasonable trade-off between sample size and event strength. Based on this criterion, there are $18 \mathrm{CAO}$ events during weak stratospheric polar vortex states (CAOW events), 14 CAO events during strong stratospheric polar vortex states (CAOS events), and $32 \mathrm{CAO}$ events during neutral stratospheric polar vortex states (CAON events). In addition, we also compare the results based on 0.7 standard deviations with those based on 1.0 and 0.5 standard deviations. We present the temporal evolution of a CAO event by dividing it into four 7-day average stages: stage 1 (days -7 to -1 ), stage 2 (days 0 to +6 ), stage 3 (days +7 to +13 ), and stage 4 (days +14 to +20 ).

To estimate the spatial coverage of extreme cold anomalies during Eurasian CAO events, we integrate the areas enclosed by grid points over Eurasia where the
SAT anomalies are below their overall wintertime 10th percentile. The integrated area is defined as the spatial coverage of Eurasian CAOs.

To examine the relationship between the stratospheric polar vortex states and Eurasian CAOs on interannual time scales, we use surface observations, reanalysis datasets, and climate models participating in phase 5 of the Coupled Model Intercomparison Project (CMIP5) simulations. These climate models used in this study that provide the historical, representative concentration pathway 4.5 (RCP4.5) and 8.5 (RCP8.5) simulations include CMCC-CMS, HadGEM2-CC, IPSL-CM5A-LR, IPSLCM5A-MR, IPSL-CM5B-LR, MIROC-ESM, MIROCESM-CHEM, MPI-ESM-LR, MPI-ESM-MR, MRI-CGCM3, and CanESM2. When there are multiple ensemble members, only the first ensemble member (r1i1p1) is used. The monthly minimum value of daily minimum temperature (TNn) defined by the Expert Team on Climate Change Detection and Indices (ETCCDI) is used to calculate the seasonal intensity of Eurasian CAOs, which is defined as the winter-mean (December-February) $\mathrm{TNn}$ anomaly area averaged $\left(40^{\circ}-65^{\circ} \mathrm{N}, 0^{\circ}-120^{\circ} \mathrm{E}\right)$ over Eurasia, and then the seasonal intensity of Eurasian CAOs is multiplied by -1 so that a positive value corresponds to strong Eurasian CAOs. The TNn index for surface observations from the National Climatic Data Center (NCDC)'s Global Historical Climatology Network (GHCNDEX) global land gridded dataset (Donat et al. 2013) is available online (www.climdex.org). The TNn index for CMIP5 model simulations from the ETCCDI archive website hosted by the Canadian Centre for Climate Modelling and Analysis (Sillmann et al. 2013a,b) is also available online (http://www.cccma.ec.gc.ca/data/ climdex/climdex.shtml).

To test the sensitivity of the interannual correlation between Eurasian CAOs and the polar vortex strength to the different definitions of the polar vortex strength, we use different methods to define the polar vortex strength. In addition to the NAM index described above, we calculate the leading principal component (PC1) of daily zonal-mean zonal wind anomalies (PClu; Limpasuvan et al. 2004), geopotential height anomaly, and air temperature anomaly area averaged over the polar cap $\left(65^{\circ}-90^{\circ} \mathrm{N}\right.$; $\mathrm{Hu}$ et al. 2018) as representatives of the polar vortex strength. The polar cap-averaged temperature anomaly (PCT) and polar cap-averaged height anomaly (PCH) are multiplied by -1 so that a positive value corresponds to a strong polar vortex. As shown in Table 1, there exist high correlations among NAM, $\mathrm{PCH}$, and $\mathrm{PClu}$ index in both the lower and midstratosphere.

To examine the potential influence of ENSO and the quasi-biennial oscillation (QBO) on the long-term relationship between the stratospheric polar vortex and 
TABLE 1. Correlation coefficients among different indices defining the stratospheric polar vortex: NAM, PC1u, PCH, and PCT indices in the midstratosphere $(50-10 \mathrm{hPa})$ and lower stratosphere $(150-70 \mathrm{hPa})$. See main text for the definition of these indices.

\begin{tabular}{|c|c|c|c|c|c|c|c|}
\hline \multicolumn{4}{|c|}{$50-10 \mathrm{hPa}$} & \multicolumn{4}{|c|}{$150-70 \mathrm{hPa}$} \\
\hline & PC1u & $\mathrm{PCH}$ & PCT & & PC1u & $\mathrm{PCH}$ & PCT \\
\hline NAM & 0.98 & 0.99 & 0.87 & NAM & 0.90 & 0.97 & 0.87 \\
\hline PC1u & - & 0.97 & 0.88 & PC1u & - & 0.86 & 0.76 \\
\hline $\mathrm{PCH}$ & - & - & 0.86 & $\mathrm{PCH}$ & - & - & 0.91 \\
\hline
\end{tabular}

Eurasian CAOs at interannual time scale, we define the Niño-3.4 index and QBO index. The Niño-3.4 index is computed as area-averaged sea surface temperature anomaly in the region $5^{\circ} \mathrm{S}-5^{\circ} \mathrm{N}, 120^{\circ}-170^{\circ} \mathrm{W}$ from the Hadley Centre Sea Ice and Sea Surface Temperature (SST) dataset, version 1 (HadISST1; Rayner et al. 2003), and CIMP5 model simulations. The QBO index is defined by zonal-mean zonal wind at $50 \mathrm{hPa}$ averaged over $10^{\circ} \mathrm{S}-10^{\circ} \mathrm{N}$ from JRA-55, NCEP reanalysis data, and CMIP5 model simulations.

We employ a two-sided Student's $t$ test to assess the statistical significance of composite analysis in this study. The number of equivalent samples is estimated using Eq. (4) in Zwiers and von Storch (1995). For the significance test of correlation coefficients, the equivalent sample size is estimated using $N^{*}=N\left[\left(1-r_{1} r_{2}\right) /\left(1+r_{1} r_{2}\right)\right]$. Here, $N^{*}$ and $N$ represent the equivalent sample size and total sample size, respectively, and $r_{1}$ and $r_{2}$ represent the lag- 1 autocorrelation coefficients of variables 1 and 2, respectively.

\section{The differences and similarities of Eurasian CAOs under different stratospheric polar vortex strength}

Figure 1 shows the spatial patterns of SAT anomalies in different stages of the three types of Eurasian CAOs. The SAT over Eurasia exhibit a significant increase in the amplitude of cold anomalies from stage 1 (Figs. 1a,e,i) to stage 2 (Figs. 1b,f,j) with minimum SAT anomalies during stage 2 followed by a gradual SAT recovery from stage 3 (Figs. 1c,g,k) to stage 4 (Figs. 1d,h,l). The spatial patterns of SAT anomalies during the later stages of CAOW and CAOS events are similar to those during extreme weak and strong polar vortex events, respectively. As shown in Figs. 1c and 1d, there are cold anomalies over the eastern United States and warming anomalies over northeastern Canada and Baffin Bay in stages 3 and 4 of CAOW events. The spatial distributions of SAT anomalies are very similar to those in later stages of weak stratospheric polar vortex events (Kolstad et al. 2010; Hitchcock and Simpson 2014; Lehtonen and Karpechko 2016; Kretschmer et al. 2018), implying that the weak stratospheric polar vortex exerts an impact on the spatial distributions of the SAT anomalies in later stages. For CAOS events, there are warm anomalies over the eastern United States and cold anomalies over Baffin Bay in stage 3 (Fig. 1g). The spatial patterns of SAT anomalies over North America are similar to those during the strong stratospheric polar vortex events (Tan et al. 2008; Kretschmer et al. 2018). Note that the strong polar vortex events usually are accompanied by warm anomalies over northern Eurasia (Tan et al. 2008; Kretschmer et al. 2018), in contrast to cold anomalies in CAOS events, suggesting that the strengthening of the stratospheric polar vortex can suppress the growth of Eurasian cold anomalies in CAOS events (Garfinkel et al. 2017).

Figure 2 shows the spatial patterns of the differences in SAT anomalies among the three types of CAO events. There are colder SAT anomalies in CAOW events over Europe than those in CAOS (Figs. 2a,b) and CAON (Figs. 2e,f) events at stages 1 and 2. This is likely because the amplitude of the negative North Atlantic Oscillation (NAO) pattern over the North Atlantic is larger in the earlier stages of CAOW events. As shown in Fig. 3, the amplitude of positive (negative) SLP anomalies in highlatitude (midlatitude) regions over the North Atlantic in CAOW events is larger than that in CAOS (Figs. 3a,b) and that in CAON events (Figs. 3e,f). Black and McDaniel (2004) reported that the preexisting negative NAO (NAM) pattern in the troposphere is favorable for a stratospheric negative NAM signal extending downward into the troposphere. Therefore, we can expect that preexisting negative NAO (NAM) pattern in the troposphere during CAOW events may be amplified by the signals extended into the troposphere from the stratosphere. As shown in Fig. S1 (see the online supplemental material), there exists a statistically significant negative NAM signal prior to the onset. It is also possible that preexisting negative NAO (NAM) acts as a bridge for the downward-extending stratospheric signals to impact on CAOs.

In the later stages of CAOs, the SAT anomalies in high-latitude regions over northern Eurasia in CAOW events are colder than those in CAOS events (Figs. 2c,d). In addition, the SAT anomalies over eastern Asia in CAOW events are also colder than those in CAON events (Figs. 2g,h). The colder SAT anomalies in CAOW events are because the amplitude of negative Arctic Oscillation $(\mathrm{AO})$ phase is larger in later stages of CAOW events relative to that in CAOS (Figs. 3c,d) and that in CAON events (Figs. 3g,h), since the negative AO phase is more evident in the later stages of CAOW events (Fig. 5). Comparing the SAT anomalies in CAON events to those in CAOS events, we can find that the SAT anomalies are colder over the regions north of $60^{\circ} \mathrm{N}$ and warmer over 


\section{CAOW}
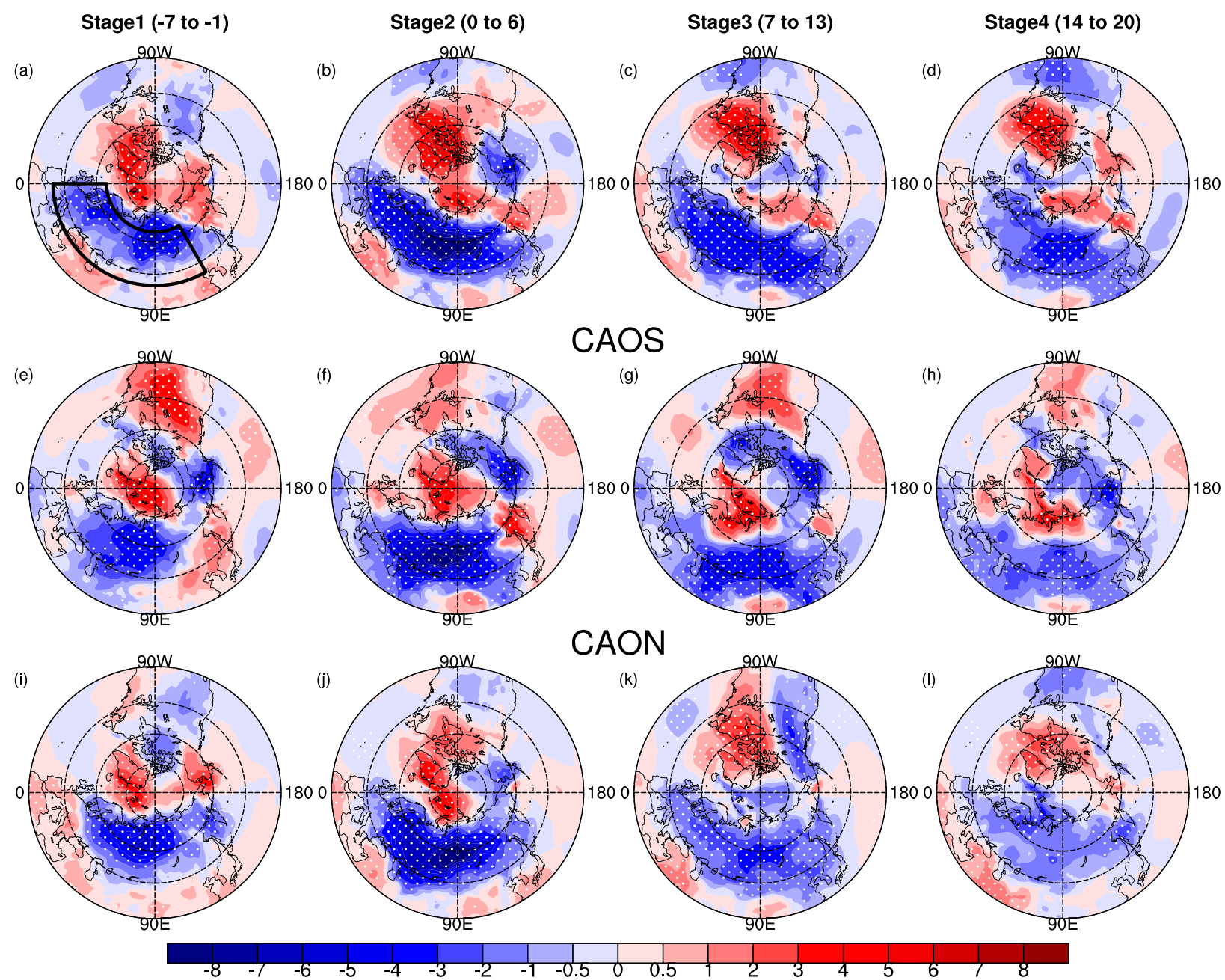

CAON
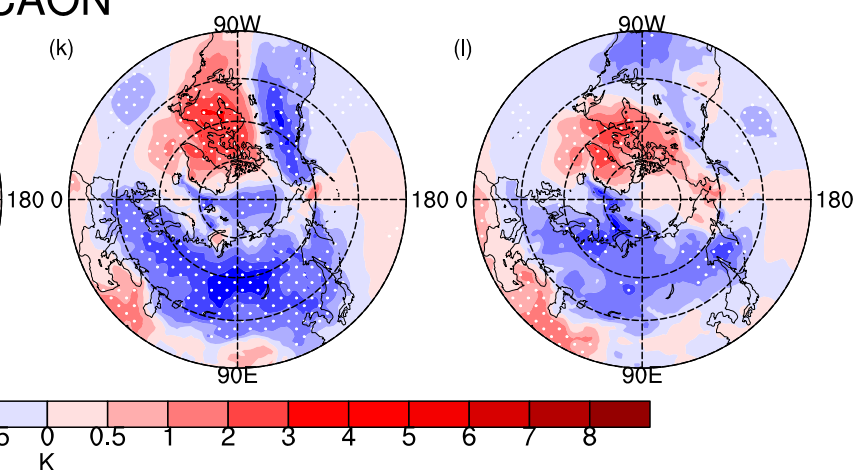

FIG. 1. (a)-(d) The composite detrended SAT anomalies during stage 1 (days -7 to -1 ), stage 2 (days 0 to +6 ), stage 3 (days +7 to +13 ), and stage 4 (days +14 to +20 ), respectively, of CAOW events. (e)-(h) As in (a)-(d), respectively, but for CAOS events. (i)-(j) As in (a)-(d), respectively, but for CAON events. The anomalies over stippled regions are statistically significant at the $95 \%$ confidence level (based on the two-sided Student's $t$ test).

the regions south of $45^{\circ} \mathrm{N}$ (Figs. $2 \mathrm{k}, 1$ ). This is associated with the spatial patterns of SLP differences, since the amplitude of positive SLP anomalies over Greenland is larger in CAON events. Although anomalously strong anticyclonic flow exists in CAOW events (Figs. 3e,f,g), the differences in SAT anomalies over central Eurasia between the CAOW and CAON events are not statistically significant (Figs. 2f,g). These results described above are also similar to those obtained from the data in the postsatellite era (see Fig. S2 in the supplemental material) and those based on 1.0 and 0.5 standard deviations (Figs. S3 and S4).

A comparison of the CAOs over northern Eurasia under different stratospheric polar vortex strengths is further highlighted in Fig. 4. Figures $4 \mathrm{a}$ and $4 \mathrm{~b}$ show the composited daily time series of differences in areaaveraged SAT anomalies over northern Eurasia and the differences in the spatial coverage of SAT anomalies for three types of CAOs, respectively. It is clear that the magnitude (Fig. 4a) and spatial coverage (Fig. 4b) of cold anomalies over northern Eurasia in CAOW events are larger than those in CAOS events at lags +4 to +10 days and those in CAON after lag +20 days. The insignificant area-averaged SAT differences between CAOW and CAON events before lag +20 days are (Figs. 4a,b) likely related to the large-amplitude air temperature recovery from cold SAT anomalies caused by diabatic heating rate anomalies (Fig. 4c). As shown 

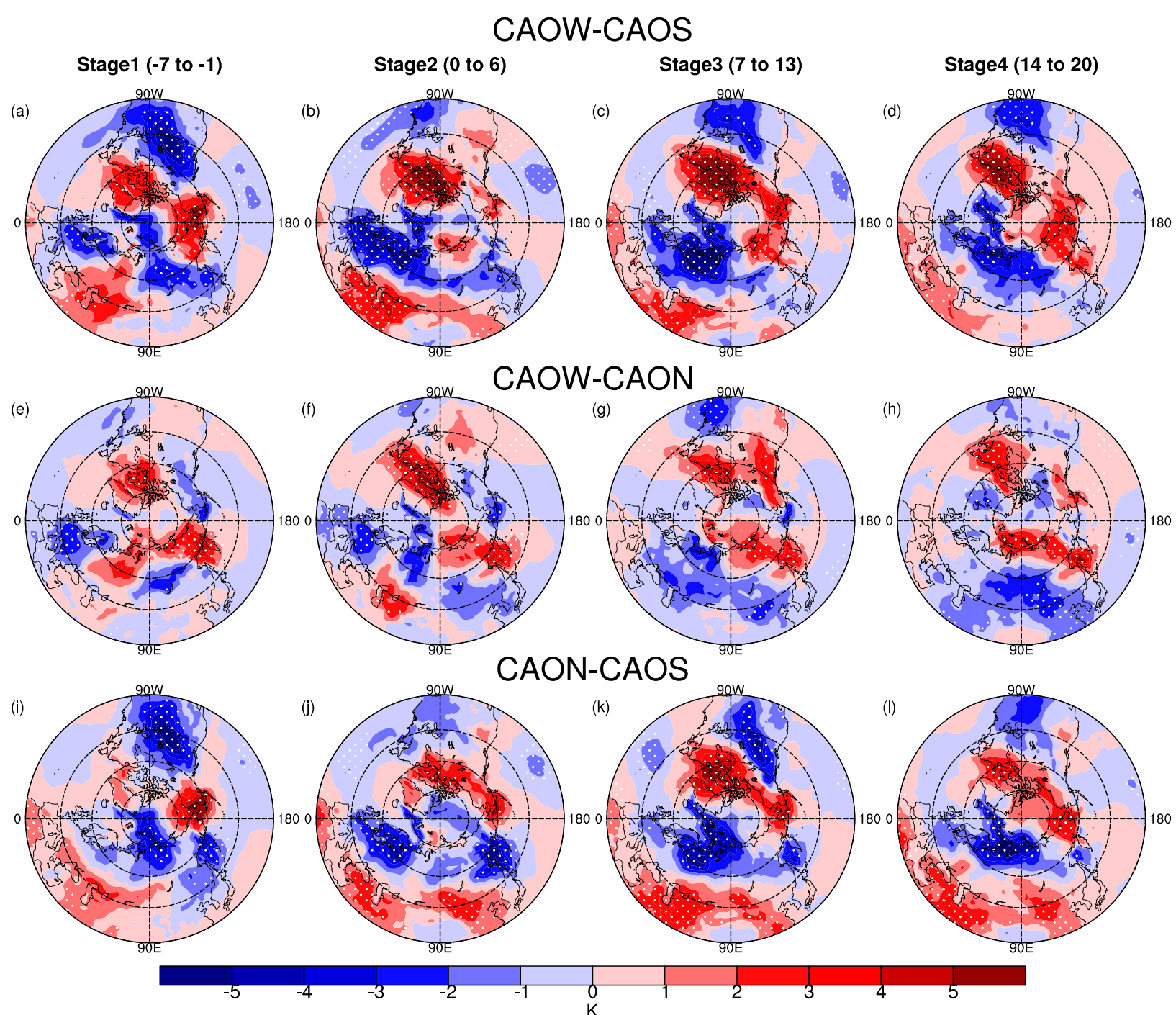

CAON-CAOS
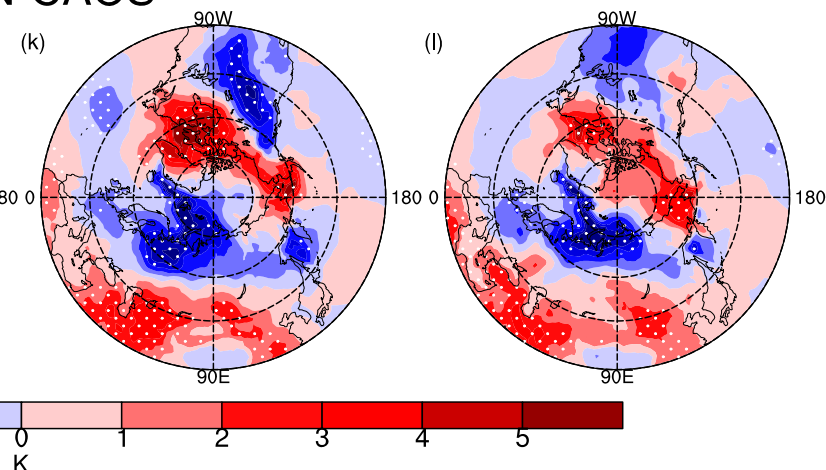

FIG. 2. (a)-(d) The spatial patterns of the differences in detrended SAT anomalies between CAOW and CAOS events during stages 1,2, 3, and 4, respectively. (e)-(h) As in (a)-(d), respectively, but for the differences between CAOW and CAON events. (i)-(l) As in (a)-(d), but for the differences between CAON and CAOS events. The SAT differences over stippled regions are statistically significant at the $95 \%$ confidence level (based on the two-sided Student's $t$ test).

in Fig. 4c, the positive diabatic heating rate anomalies are evident after the onset with maximum value at lag +2 days for these three types of CAOs, indicating that the cooling of SAT gradually slows down. The stronger anticyclonic flow over Eurasia at earlier stages of CAOW events can lead to a stronger cold advection than that in CAON events. It is reasonable that the stronger cold advection in CAOW events leads to larger temperature differences between the surface and the atmosphere. The larger temperature gradients near the surface lead to more surface heat to be transported into the atmosphere. As shown in Fig. 4d, there are larger positive sensible heat flux anomalies in CAOW events than those in CAON events, which lead to a larger increase in diabatic heating rate in CAOW events than that that in CAON events. Although the stronger cold advection exists at stages 2 and 3 in CAOW events (Figs. 3f,g), larger diabatic heating rate anomalies in CAOW events likely offset, to some degree, the cooling effect caused by the stronger cold advection, and thus make the area-averaged SAT differences between CAOW and CAON events look insignificant (Figs. 4a,b).

In addition, Table 2 shows the duration of the three types of CAOs under different thresholds defining the strong and weak polar vortex states. It can be found that the duration of CAOW events is statistically longer than that of CAOS $(p<0.05)$ and that of CAON events $(p<0.1)$ under the three types of thresholds. 


\section{CAOW-CAOS}
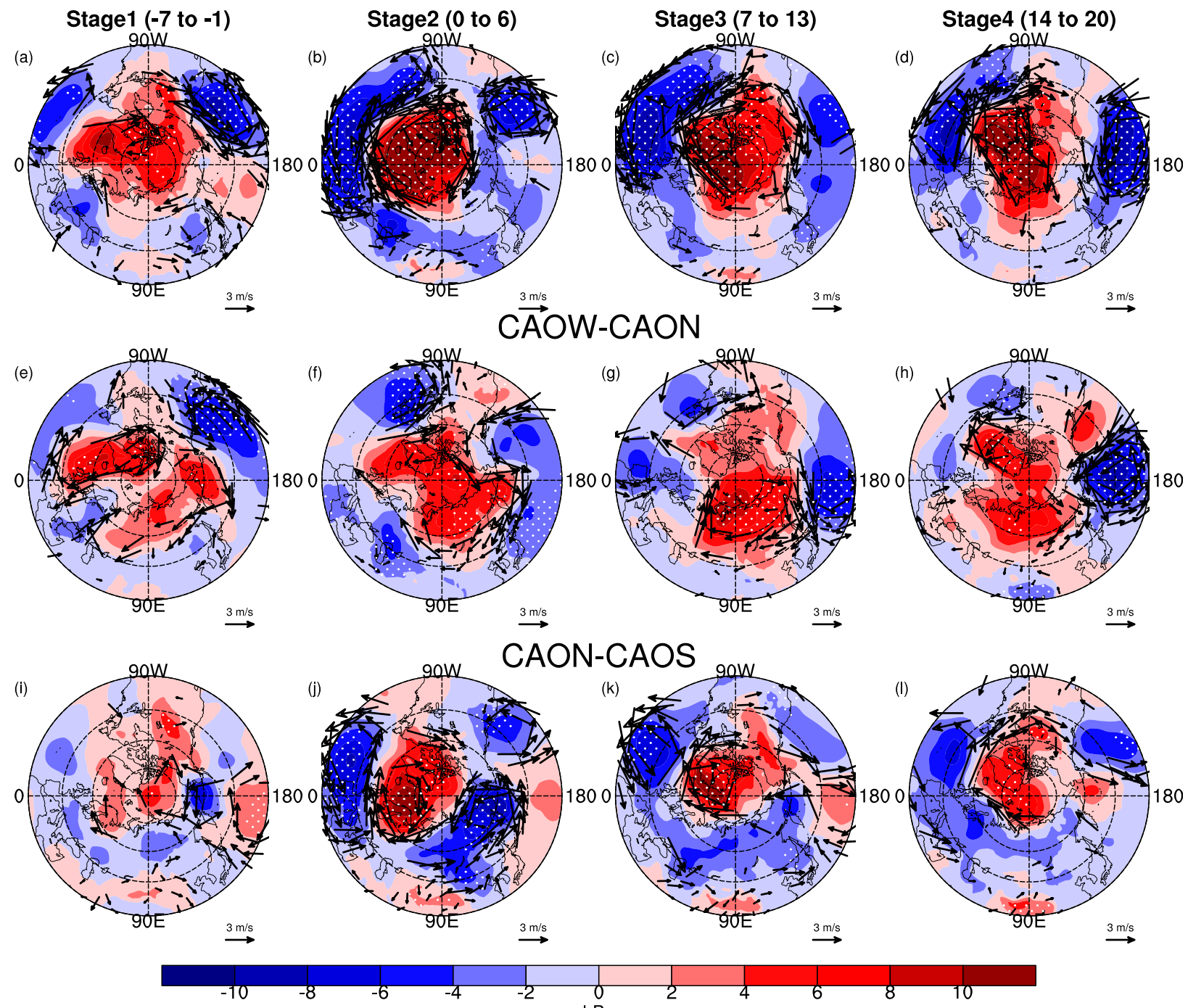

FIG. 3. (a)-(d) The composite spatial patterns of the differences in detrended SLP anomalies (shading) and near-surface horizontal wind anomalies (vectors) between CAOW and CAOS events during stages 1,2,3, and 4, respectively. (e)-(h) As in (a)-(d), respectively, but for the differences between CAOW and CAON events. (i)-(1) As in (a)-(d), respectively, but for the differences between CAON and CAOS events. The differences over stippled regions are statistically significant at the $95 \%$ confidence level (based on the two-sided Student's $t$ test). Only horizontal winds statistically significant at the $95 \%$ confidence level are shown.

The duration of CAON events is also longer than that of CAOS events, although the difference is statistically insignificant.

Park et al. (2011) categorized cold surges over East Asia with respect to surface AO phases and found that the magnitude of cold surges in the negative AO phase is larger than that in the positive AO phase, and the duration of cold surges in the negative AO phase is also longer. The differences between CAOW and CAOS events in our analysis are in agreement with theirs. Note that the classification of Eurasian CAOs with respect to the stratospheric polar vortex strength in our study suggests that the differences in their magnitude, spatial coverage, and duration between the two types are likely linked to the influence of the stratospheric polar vortex. Garfinkel et al. (2017) also defined Eurasian wintertime "cold snaps" and indicated that the cold snaps starting with a weak 150-hPa polar vortex persist for much longer than those starting with a strong $150-\mathrm{hPa}$ polar vortex. Note, however, that we categorize Eurasian CAOs into three types based on the polar vortex strength from the lower to midstratosphere and find that the features of the 

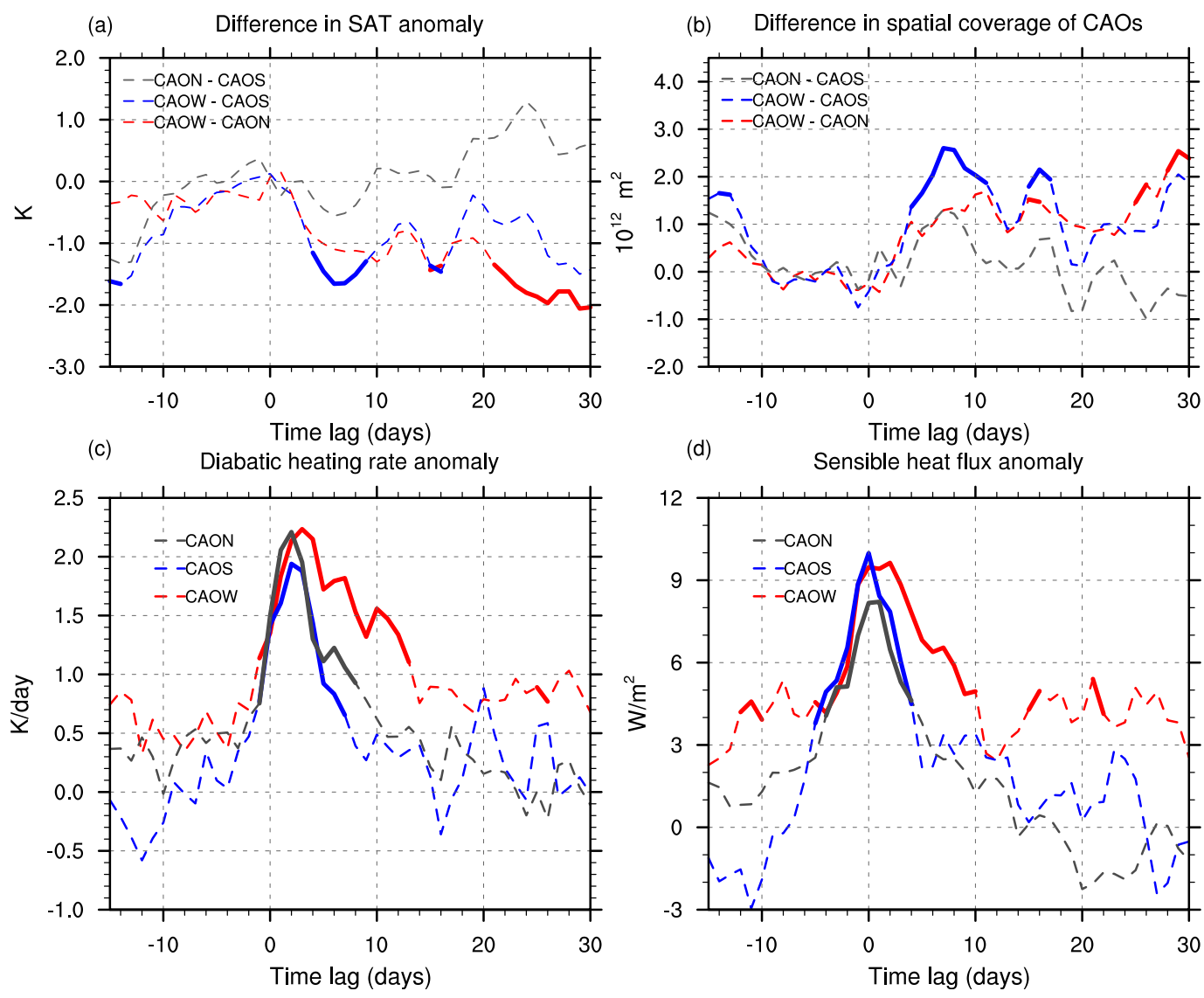

FIG. 4. Composites of daily time series of differences in area-averaged SAT anomalies over northern Eurasia $\left(40^{\circ}-65^{\circ} \mathrm{N}, 0^{\circ}-120^{\circ} \mathrm{E}\right)$ for three types of CAOs. (b) As in (a), but for the differences in the spatial coverage anomalies for three types of CAOs. Red, blue, and gray lines indicate the differences between CAOW and CAON events, between CAOW and CAOS events, and between CAON and CAOS events, respectively. (c) Composites of daily time series of near-surface diabatic heating rate anomaly area averaged over northern Eurasia $\left(40^{\circ}-65^{\circ} \mathrm{N}\right.$, $0^{\circ}-120^{\circ} \mathrm{E}$ ) for CAOW events (red), CAOS events (blue), and CAON events (gray). (d) As in (c), but for the sensible heat net flux anomalies. Day 0 refers to the onset. Thick line segments indicate differences (anomalies) significantly different from zero at the 95\% confidence level (based on the two-sided Student's $t$ test).

three types of CAOs are different from each other, implying that the polar vortex strength plays a vital role in shaping the differences in the features of Eurasian CAOs. In addition, there are no details about how the stratospheric polar vortex with different strengths affects the properties of Eurasian CAOs in the study of Garfinkel et al. (2017), and this issue is further discussed in section 4.

\section{The role of stratospheric polar vortex strength in Eurasian CAOs}

To understand how the stratospheric polar vortex impacts Eurasian CAOs, we first examine the evolution of tropospheric circulation patterns leading to Eurasian CAOs. Figure 5 shows the 500-hPa geopotential height anomalies and Plumb wave activity flux (Plumb 1985) anomalies of all waves in four stages of the three types of CAOs. In earlier stages (i.e., stages 1 and 2) of the three types of CAOs, there exist evident negative height anomalies over eastern Eurasia and positive height anomalies over upstream regions of negative height anomalies. In addition, a negative NAO-like pattern of height anomalies can be found in CAOW and CAON events, whereas the amplitude of the negative NAO pattern in CAOW events is larger than that in CAON events.

TABLE 2. Durations (days) of the three types of Eurasian CAOs under different thresholds defining the strong and weak polar vortex states.

\begin{tabular}{lccc}
\hline \hline & $1.0 \mathrm{std} \mathrm{dev}$ & $0.7 \mathrm{std} \mathrm{dev}$ & $0.5 \mathrm{std} \mathrm{dev}$ \\
\hline CAOW & 10.5 & 9.8 & 9.0 \\
CAOS & 5.4 & 4.7 & 5.7 \\
CAON & 6.4 & 6.7 & 6.5 \\
\hline
\end{tabular}




\section{CAOW}
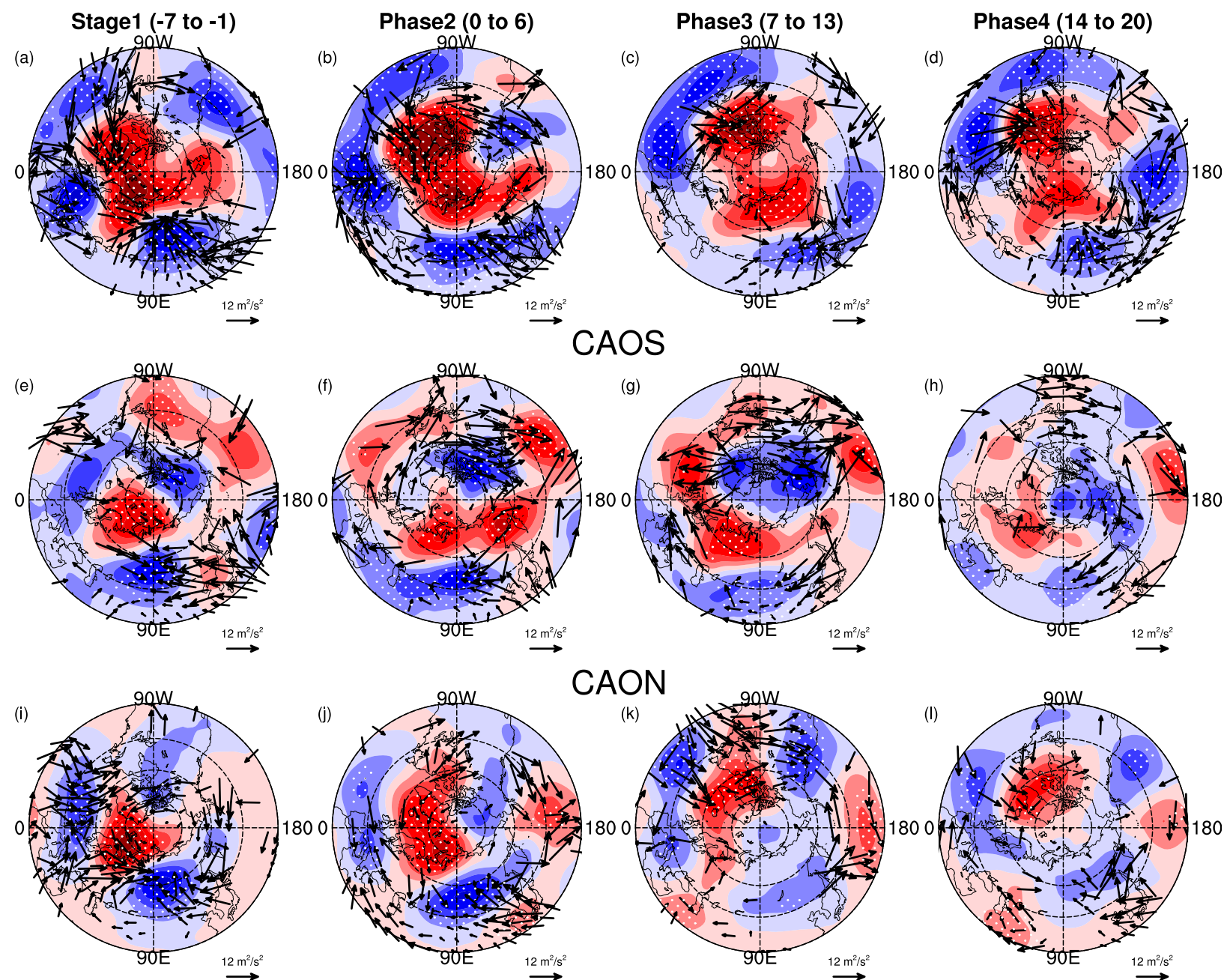

\section{CAON}
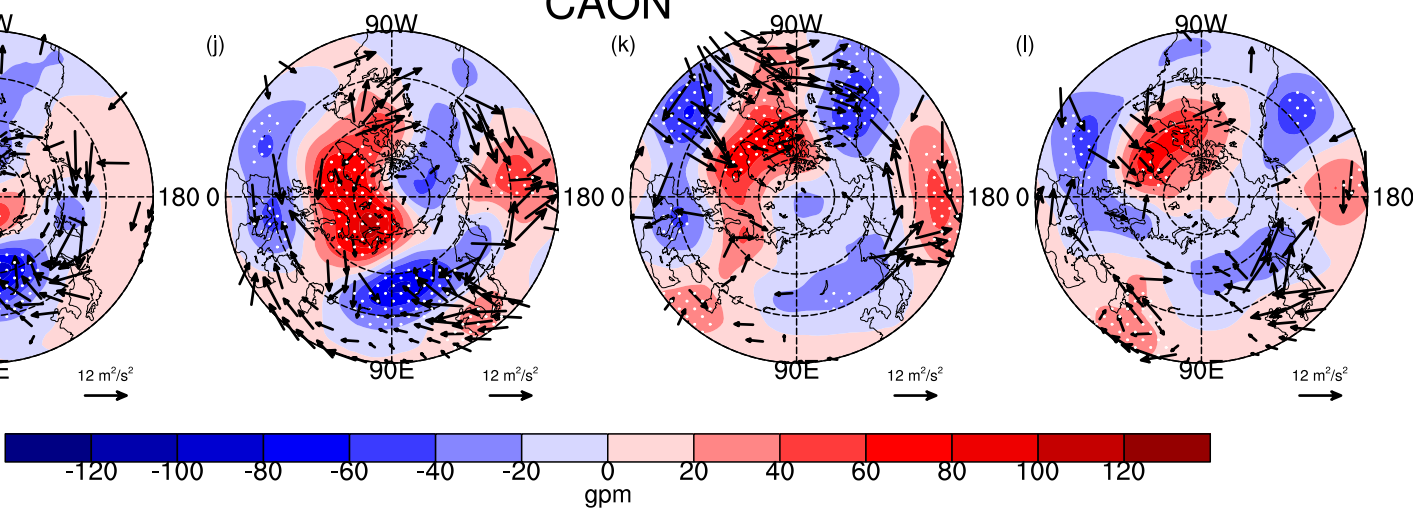

FIG. 5. (a)-(d) The composite detrended 500-hPa geopotential height anomalies (shading) and Plumb wave flux anomalies (vectors) during stages 1, 2, 3, and 4, respectively, of CAOW events. (e)-(h) As in (a)-(d), respectively, but for CAOS events. (i)-(j) As in (a)-(d), respectively, but for CAON events. The height anomalies over stippled regions are statistically significant at the $95 \%$ confidence level (based on the two-sided Student's $t$ test). Only wave fluxes statistically significant at the $95 \%$ confidence level are shown.

Thus the SAT over Europe is colder in CAOW events than that in CAON events (Fig. 2). As indicated by Plumb wave fluxes, the anomalous wave fluxes over the upstream blocking region propagate eastward and merge over eastern Eurasia in earlier stages of the three types of CAOs. More evidently massive anomalous waves from low-latitude regions especially from the lowlatitude Pacific propagate poleward and merge over northeastern Eurasia. These anomalous wave activities lead to anomalous convergences of wave fluxes over northeastern Eurasia, which weaken the westerly wind over this region and create favorable conditions for southward advection of cold air masses. This indicates that the wave fluxes from the low-latitude Pacific region play an important role in the earlier stages of Eurasian CAOs.

During stages 3 and 4 of CAOW events (Figs. 5 c,d), there are evident negative AO patterns of geopotential height anomalies, which are likely linked to the influence of the weakened stratospheric polar vortex (e.g., Kolstad et al. 2010; Hitchcock and Simpson 2014; Kidston et al. 2015; Huang et al. 2017). Previous studies pointed out that the time scale for some anomalous weak vortex signals in the midstratosphere extending into the lower troposphere is about 15 days, and the anomalous signals in the lower 
stratosphere can last for more than 60 days (e.g., Baldwin and Dunkerton 2001; Hitchcock et al. 2013). Therefore, the area-averaged differences in SAT anomalies between CAOW and CAON events over northern Eurasian are more statistically significant after a longer lag time (Fig. 4a). For the CAOS events, the positive height anomalies over the regions north of $60^{\circ} \mathrm{N}$ are evidently weakened during stages 3 and 4 (Figs. 5g,h). Although there are no positive height anomalies over northern Eurasia, the negative NAO patterns are still evident during stages 3 and 4 of CAON events (Figs. 5k,l). The negative NAO patterns lead to colder SAT in high-latitude regions over Eurasia in CAON events than those in CAOS events (Figs. 2k,l). The anomalous wave activities over Eurasia are weakened in later stages than those in earlier stages of the three types of CAOs, but the anomalous Plumb wave fluxes are still evident in stages 3 and 4 of CAOW events.

Figure 6 shows the zonal-mean geopotential height anomalies and Plumb wave flux anomalies in the Eastern Hemisphere $\left(0^{\circ}-180^{\circ} \mathrm{E}\right)$. In the CAOW events, there are positive height anomalies north of $60^{\circ} \mathrm{N}$ and negative height anomalies south of $60^{\circ} \mathrm{N}$. It is clear that the positive geopotential height anomalies at high latitudes in the stratosphere can extend downward into the troposphere (Figs. 6a-d), thereby modifying the tropospheric circulation. For CAOS events, there is a vertical dipole structure in the geopotential height anomalies at high latitudes with negative anomalies in the stratosphere and positive anomalies in the troposphere (Figs. 6e-g). The stratospheric negative height anomalies gradually extend downward near the tropopause (Figs. 6e-g) and enter the troposphere in the polar region at stage 4 (Fig. 6h). Note that the positive tropospheric height anomalies in the region north of $60^{\circ} \mathrm{N}$ are gradually weakened accompanied by the strengthening and downward extension of the stratospheric negative height anomalies and have disappeared in stage 4 (Fig. 6h). No significant height anomalies exist in the stratosphere in CAON events (Figs. 6i-1); thus, the evolution of tropospheric positive height anomalies at high latitudes are less likely linked to the influence of the stratosphere.

There are anomalous poleward Plumb wave fluxes in the earlier stages of CAOW events (Figs. 6a,b) that give rise to anomalous convergence of wave activities around $40^{\circ}-60^{\circ} \mathrm{N}$. This feature is consistent with anomalous poleward Plumb fluxes over Eurasia as shown in Fig. 5. In addition, there exist anomalous upward Plumb wave fluxes into the stratosphere at stage 1 of CAOW events (Fig. 5a). For CAOS events, the anomalous upward wave flux originated from the positive height anomalies poleward of $60^{\circ} \mathrm{N}$ in the troposphere is reflected toward the low-latitude upper troposphere and lower stratosphere. The anomalous poleward wave fluxes from low latitudes together with the anomalous equatorward wave fluxes lead to anomalous convergence of wave fluxes at approximately $45^{\circ} \mathrm{N}$ at stages 1 and 2 (Figs. 6a and 6b, respectively). In stage 1 of CAON events (Fig. 6i), there are evident anomalous poleward wave fluxes at low latitudes and anomalous upward and equatorward wave fluxes poleward of $60^{\circ} \mathrm{N}$. Also note that the anomalous wave fluxes are mainly confined in the troposphere during CAON events, and less statistically significant wave fluxes can be found in the stratosphere. In the later stages of CAOW events, the stratospheric wave fluxes are anomalously downward. In addition, there exist anomalous upward wave fluxes into the stratosphere at stage 4 of CAOS events. This feature of wave fluxes is favorable for the recovery of the stratospheric polar vortex from the anomalous state. Previous studies also reported that there exist anomalous downward and upward wave fluxes during the later stage of weak and strong stratospheric polar vortex events (e.g., Limpasuvan et al. 2004, 2005; Kuroda 2008; Huang et al. 2017), respectively.

Previous studies have indicated that the variability in the stratosphere can impact the tropospheric circulation by several proposed mechanisms (e.g., Hoskins et al. 1985; Black 2002; Plumb and Semeniuk 2003; Cai and Ren 2007; Lubis et al. 2018b), as discussed in section 1. Cai and Ren (2007) indicated that a reduction of airmass supply over the polar cap in the stratosphere tends to lead to a negative SLP anomaly over the polar region, and vice versa. Figure 7 shows the stratospheric airmass anomalies integrated north of $60^{\circ} \mathrm{N}$ on the different isentropic surfaces during the three types of CAOs. As shown in Fig. 7a, there exists anomalously increased air mass in CAOW events. We can see that the SLP anomalies north of $60^{\circ} \mathrm{N}$ in CAOW events are larger than those in CAOS and those in CAON events (Fig. 3). The positive airmass anomalies are favorable for the maintenance of the anomalous anticyclonic flow at high latitudes in CAOW events, which leads to long-lasting cold anomalies. Although stratospheric negative height anomalies cannot extend downward into the lower troposphere in CAOS events, there exists anomalously decreased stratospheric air mass in the polar region (Fig. 7b). Thus it is possible that the decreased amplitude of anticyclonic flow at stages 3 and 4 are linked to the significant stratospheric airmass anomalies. There are almost no statistically significant stratospheric airmass anomalies in CAON events (Fig. 7c), indicating a lack of stratospheric influence.

\section{The relationship between Eurasian CAOs and the stratospheric polar vortex on interannual time scales}

Finally, we examine the relationship between the anomalous stratospheric polar vortex states and Eurasian CAOs 

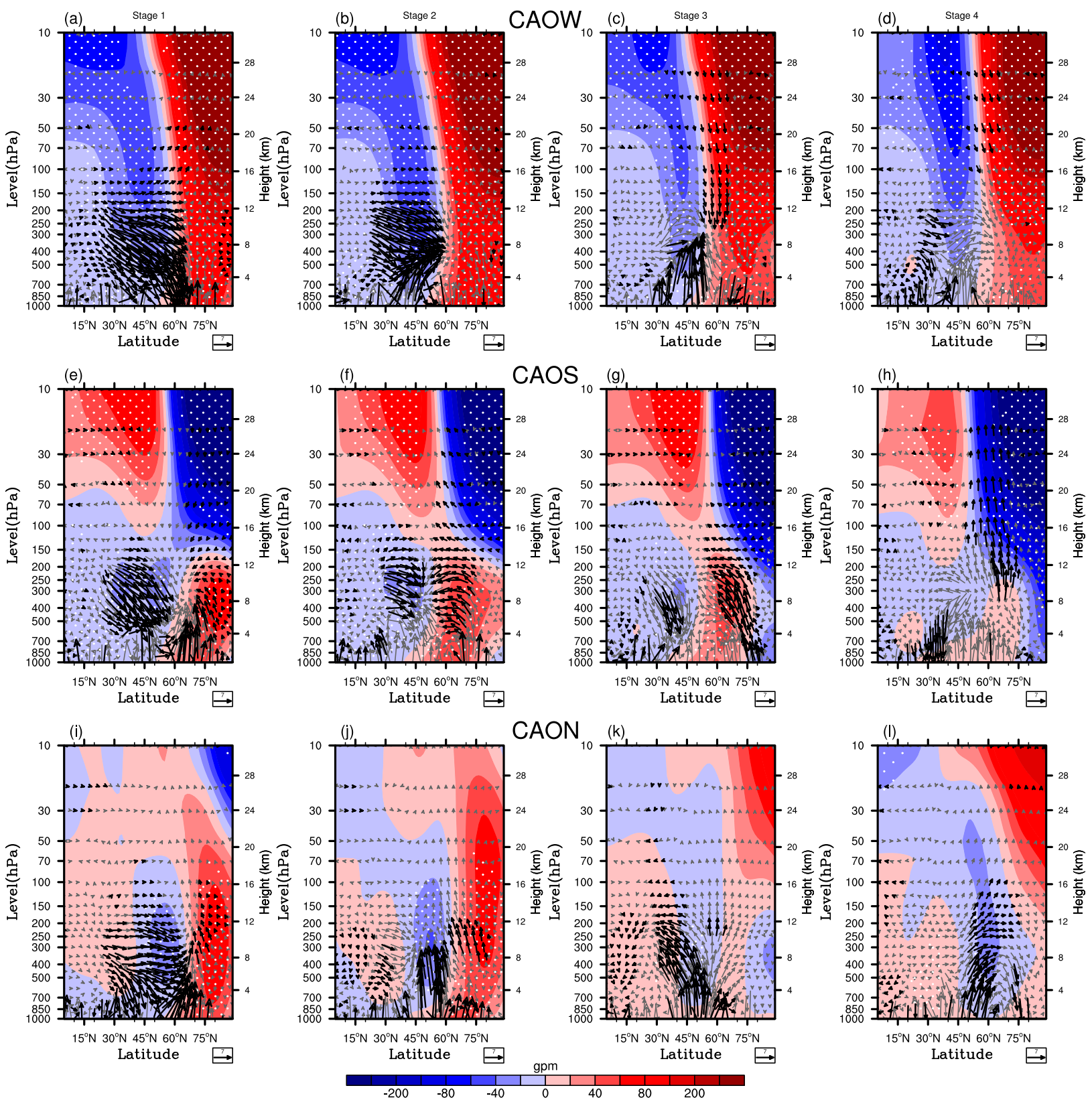

FIG. 6. (a)-(d) Latitude-pressure sections of geopotential height anomalies (shading) and Plumb wave flux anomalies (vectors) averaged in the Eastern Hemisphere $\left(0^{\circ}-180^{\circ}\right.$ E) during stages 1, 2, 3, and 4, respectively, of CAOW events. (e)-(h) As in (a)-(d), respectively, but for CAOS events. (i)-(j) As in (a)-(d), respectively, but for CAON events. The geopotential height anomalies over stippled regions are statistically significant at the $95 \%$ confidence level, and the black arrows represent that the wave fluxes are statistically significant at the $95 \%$ confidence level (based on the two-sided Student's $t$ test).

on interannual time scales using both reanalysis data and CMIP5 climate model simulations. Considering that the temporal variability and the spatial patterns of the NAM differ greatly across the different models (Kolstad et al. 2010), we therefore use PCH and PCT index as the representatives of stratospheric polar vortex strength. Figure 8 shows scatterplots of the detrended $\mathrm{PCH}$ index and detrended Eurasian $\mathrm{CAO}$ index derived from different datasets. There exists a statistically significant correlation $r$ between the lowerstratospheric polar vortex strength $(150-70 \mathrm{hPa})$ and Eurasian CAO index (Fig. 8a) in both reanalyses $(-0.58$ for JRA-55, $p<0.01 ;-0.57$ for NCEP, $p<0.01$ ) over the period 1958-2016 and CMIP5 simulations $(r=-0.35$, 

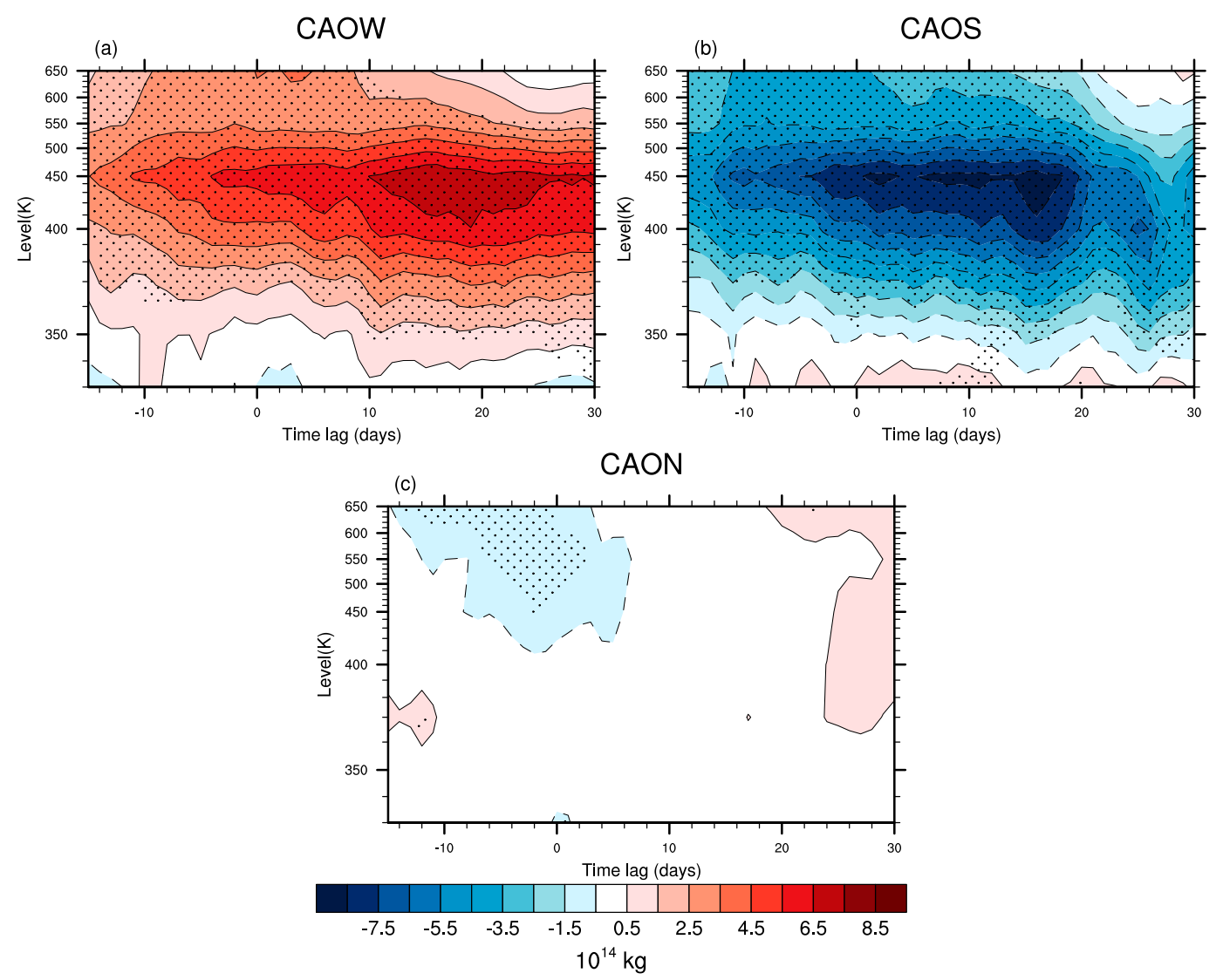

FIG. 7. (a) Composited time-height variations of isentropic airmass anomalies $\left(10^{14} \mathrm{~kg}\right)$ integrated over the polar region $\left(60^{\circ}-90^{\circ} \mathrm{N}\right)$ in the stratosphere during CAOW events. (b),(c) As in (a), but for CAOS and CAON events, respectively. The airmass anomalies over stippled regions are statistically significant at the $95 \%$ confidence level (based on the two-sided Student's $t$ test).

$p<0.01$ ) over the period 1958-2005. Garfinkel et al. (2017) also found that there exists stronger correlation between the stratospheric polar vortex strength at $150 \mathrm{hPa}$ and Eurasian SAT anomalies on shorter time scales (1989/90-2011/12). The absolute value of correlation coefficients obtained from the reanalysis dataset are larger than those obtained from the CMIP5 simulations (Fig. 8a). In addition, statistically significant correlations between the polar vortex strength and Eurasian CAO index (Fig. 8b) also exist under RCP4.5 $(r=-0.40, p<0.01)$ and RCP8.5 scenarios $(r=-0.42$, $p<0.01$ ) over the period 2006-60. Interestingly, the interannual relationship between the lower-stratospheric polar vortex and Eurasian CAOs in the future is larger than that in the past, indicating a strengthening relationship between the stratospheric polar vortex and Eurasian CAOs in the future. Statistically significant correlations also exist between the midstratospheric polar vortex strength $(50-10 \mathrm{hPa})$ and Eurasian CAO index in the past (Fig. 8c) and in the future (Fig. 8d), but the interannual correlation are evidently lower than those in the lower stratosphere. Note that the interannual correlation between the polar vortex strength based on the PCT index and Eurasian CAO index (Figs. S5a-d in the online supplemental material) are weaker than those based on the $\mathrm{PCH}$ index.

We further examine the long-term change of the Eurasian CAO index and the potential factors influencing the long-term change. Figure 9 shows the normalized time series of the Eurasian CAOs index, lower-stratospheric PCH index (150-70 hPa), QBO index, and Niño-3.4 index in different datasets. The seasonal intensity of Eurasian CAOs show a decreasing trend in the past 60 years based on the surface observations with a linear trend of -0.28 decade $^{-1}$ (Fig. 9a). The result from CMIP5 multimodel mean also exhibits a decreasing trend in Eurasian CAOs intensity with a linear trend of -0.23 decade $^{-1}$ over the period 1958-2005. Previous studies indicated that midlatitude regions over Eurasia have gone through anomalously cold anomalies in recent winters (i.e., Cohen et al. 2014; Kretschmer et al. 2018; Garfinkel et al. 2017). Some studies have linked 
(a)

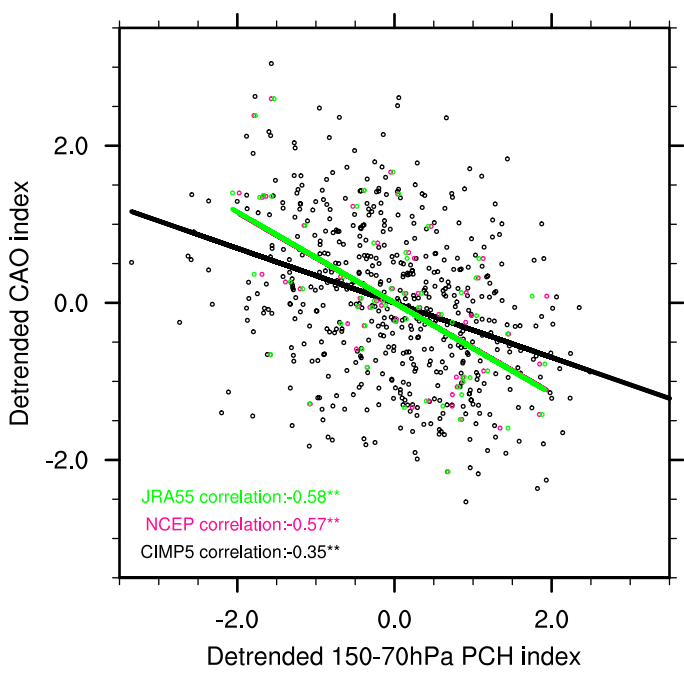

(c)

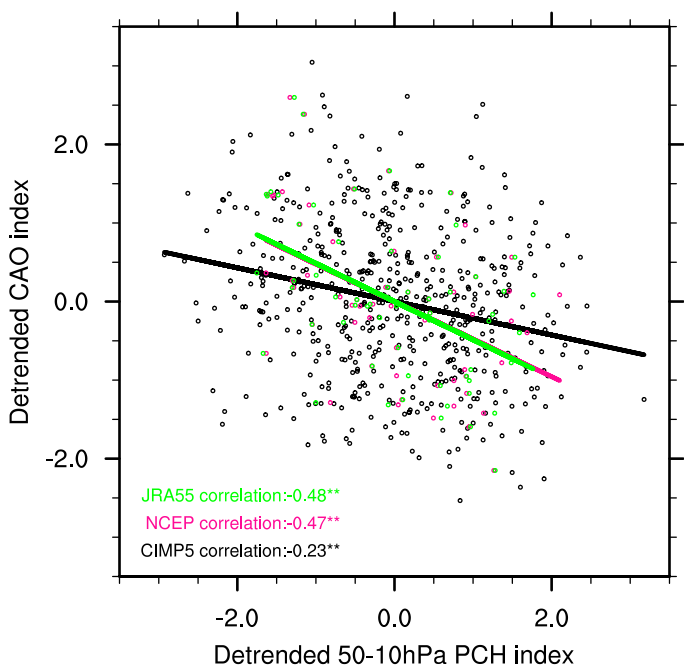

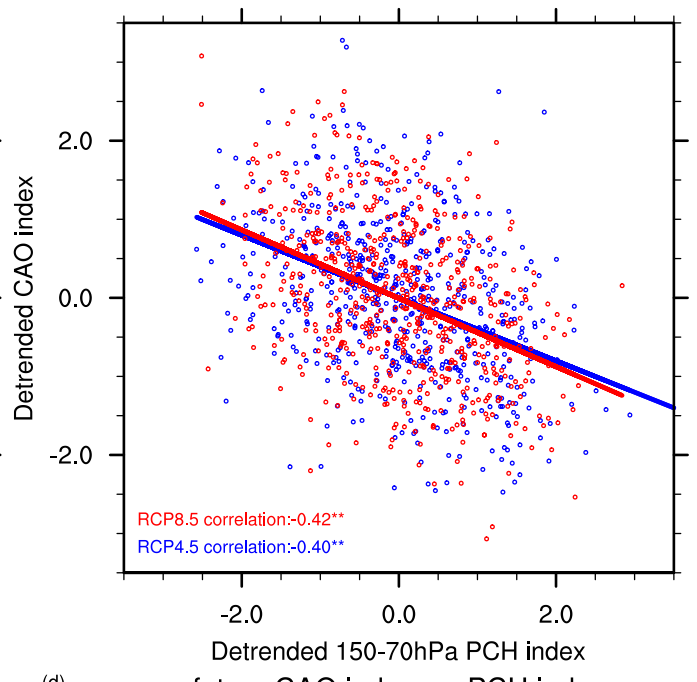

(d)

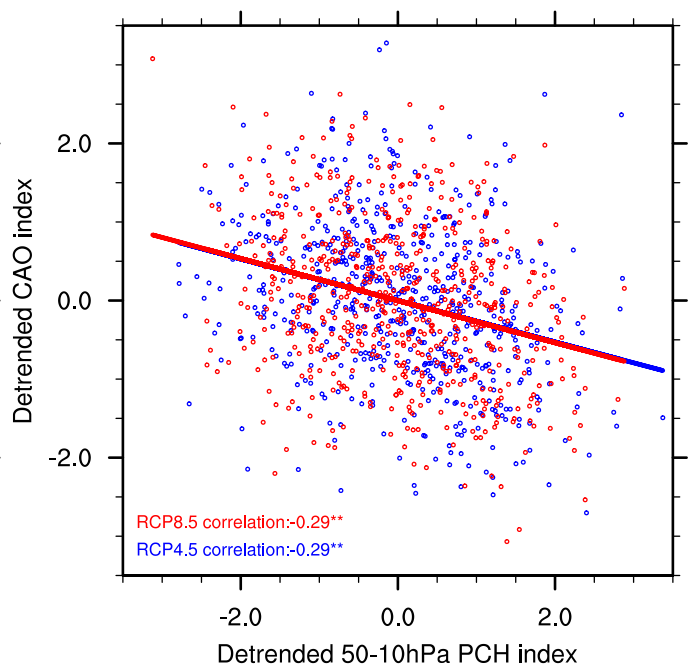

FIG. 8. (a) Scatterplots of the detrended lower-stratospheric PCH index (150-70 hPa) and the detrended Eurasian CAO index derived from different datasets. Pink, green, and black circles represent the NCEP reanalysis and JRA-55 over the period 1958-2016 and 11 CMIP5 model simulations over the period 1958-2005, respectively. (b) As in (a), but for the results under RCP4.5 (blue) and RCP8.5 (red) scenarios over the period 2006-60. (c),(d) As in (a) and (b), respectively, but for the detrended midstratospheric PCH index (50-10 hPa). The solid line denotes the linear regression. The correlation coefficient between stratospheric $\mathrm{PCH}$ index and Eurasian CAO index is shown in the bottom-left corner of each panel. Two asterisks indicate that the correlation coefficient is statistically significant at the $99 \%$ confidence level.

the Eurasian winter cooling trend to weak stratospheric polar vortex (i.e., Kretschmer et al. 2018; Garfinkel et al. 2017). As shown in Fig. 9a, the Eurasian CAOs index based on the surface observations shows an increasing trend $\left(0.31\right.$ decade $\left.^{-1}\right)$ over the period 1989-2009; the lower-stratospheric polar vortex also shows a trend toward the weakened state over this period with a linear trend of -0.99 decade $^{-1}$ in the NCEP reanalysis dataset and -0.95 decade $^{-1}$ in the JRA- 55 dataset. Note that there are no statistically significant trends in the lower-stratospheric polar vortex strength over the period 1958-2016 in these two reanalysis datasets (Fig. 9b), whereas the CMIP5 multimodel mean results show a slightly decreasing trend $\left(-0.08\right.$ decade $\left.^{-1}\right)$. In addition, there are also no significant linear trends in the QBO index (Fig. 9c) and Niño-3.4 index (Fig. 9d) over the period 1958-2016. Thus, the longterm decreasing trend of the Eurasian CAO index is likely linked to global surface air temperature warming.

Figure 10 further shows the normalized time series of the Eurasian CAO index, lower-stratospheric $\mathrm{PCH}$ 

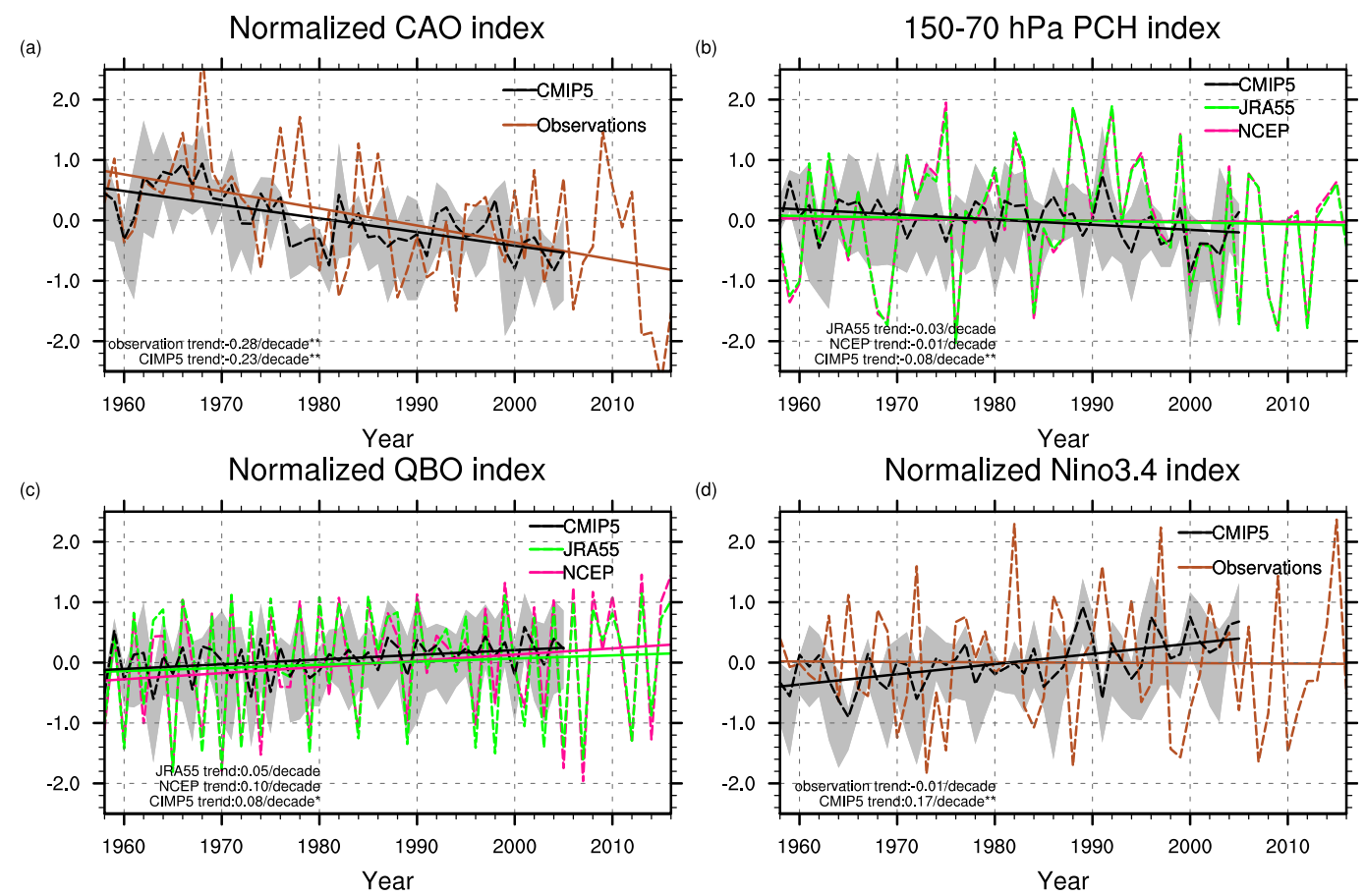

FIG. 9. (a) Normalized time series of the Eurasian CAO index from surface observations (brown) over the period 1958-2016 and the ensemble mean of 11 CMIP5 models (black) over the period 1958-2005. (b) Normalized time series of the lower-stratospheric PCH index from JRA-55 (green) and the NCEP reanalysis (pink) from 1958 to 2016 and the ensemble mean of CMIP5 models (black) from 1958 to 2005. (c) As in (b), but for the normalized QBO index. (d) As in (a), but for the normalized Niño-3.4 index. The shading represents the interquartile ensemble spread (between the 25th and 75 th quantiles). Solid lines in each panel indicate the linear trend of these indices, and the trend value is shown in the bottom-left corner of each panel. One asterisk (two asterisks) indicates that the linear trend value is statistically significant at the $90 \%(99 \%)$ confidence level.

index (150-70 hPa), QBO index, and Niño-3.4 index under RCP4.5 and RCP8.5 scenarios. We can see that there exist negative linear trends in the intensity of Eurasian CAOs under both RCP4.5 $\left(-0.31\right.$ decade $\left.^{-1}\right)$ and RCP8.5 ( -0.40 decade $\left.^{-1}\right)$ scenarios over the period 2006-60 (Fig. 10a). Also note that there are statistically significant negative linear trends in the lower-stratospheric polar vortex strength with a linear trend of -0.18 decade $^{-1}$ under RCP4.5 and -0.27 decade $^{-1}$ under RCP8.5 over the period 2006-60 (Fig. 10b). The negative trends of polar vortex strength are likely linked to the increasing trends of the Niño-3.4 index that show a trend of 0.29 decade $^{-1}$ under RCP4.5 and a trend of 0.37 decade $^{-1}$ under RCP8.5 over this period (Fig. 10d). There are no statistically significant linear trends in the QBO index under RCP4.5 and RCP8.5 scenarios in the future (Fig. 10c). Considering that there exists significant negative correlation between detrended polar vortex strength and the intensity of the Eurasian CAO on interannual time scales under RCP4.5 and RCP8.5 scenarios, the negative trend of polar vortex will likely contribute to a positive trend of the Eurasian CAO index in the future. But the global surface temperature warming caused by the increasing greenhouse gas emissions will likely lead to a larger decreasing trend in the intensity of Eurasian CAOs under RCP4.5 and RCP8.5 scenarios, and the combined effect is that the intensity of Eurasian CAOs will be decreasing in the future. A further study is still needed to answer what the relative contributions of weakening stratospheric polar vortex and the increasing greenhouse gas emissions to the variations of Eurasian CAOs are in the future.

To further understand the relationship between the stratospheric polar vortex and Eurasian CAOs, we examine the relationship between the frequency of the extreme stratospheric polar vortex states and the frequency of Eurasian cold days in winter, and the relationship between the duration of the extreme stratospheric polar vortex events and the duration of Eurasian cold events on interannual time scales using the JRA-55 dataset. The weak (strong) polar vortex days are defined as these days in which the normalized indices of the polar vortex strength are lower (larger) than $-1(+1)$. The duration 
(a)

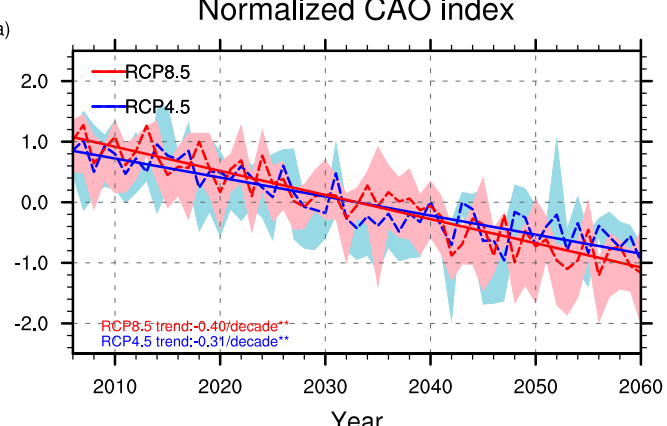

Normalized QBO index

(c)

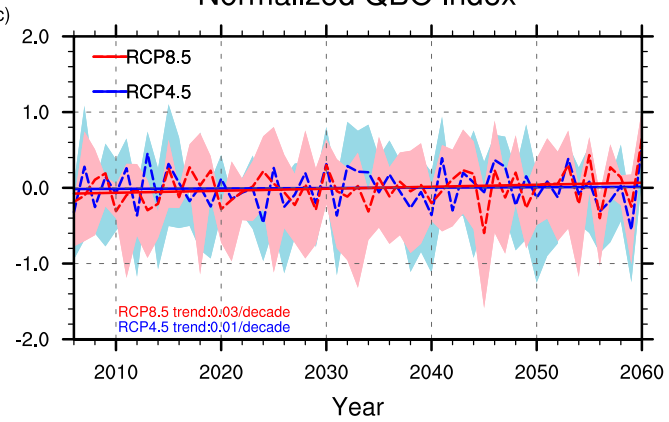

(b)

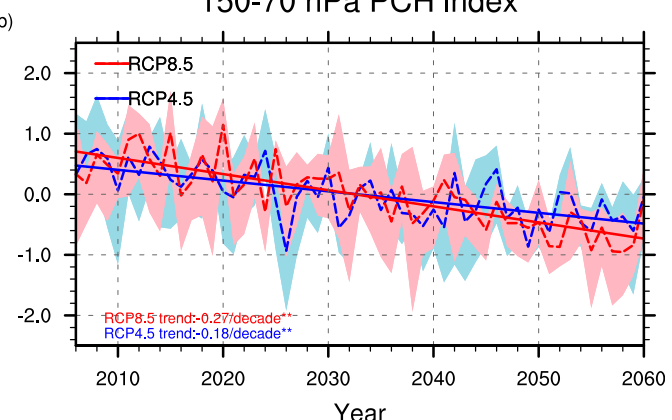

Normalized Nino3.4 index

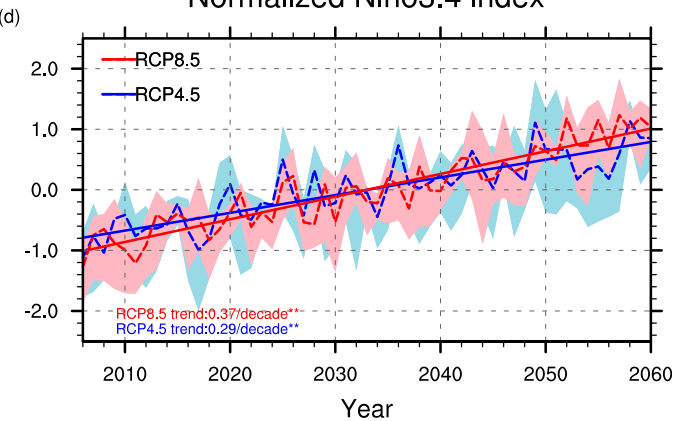

FIG. 10. (a) Normalized time series of the Eurasian CAO index from the ensemble mean of 11 CMIP5 models under RCP4.5 (blue) and RCP8.5 (red) scenarios over the period 2006-60. (b)-(d) As in (a), but for the normalized time series of the low-stratospheric polar vortex strength index, the normalized QBO index, and the normalized Niño-3.4 index, respectively. The shading represents the interquartile ensemble spread (between the 25th and 75th quantiles). Solid lines in each panel indicate the linear trend of these indices over the period 2006-60, and the trend value is shown in the bottom-left corner of each panel. Two asterisks indicate that the linear trend value is statistically significant at the $99 \%$ confidence level.

of the extreme polar vortex events is defined as the consecutive extreme polar vortex days. The definition of Eurasian cold days and the duration of Eurasian cold events are described in section 2 .

Figure 11 shows the scatterplots of the detrended frequency and duration of Eurasian cold days and the detrended frequency and duration of the extreme stratospheric polar vortex states over the period 1958 2016. The seasonal frequencies of weak polar vortex states based on the NAM, PClu, and PCT index all positively correlate with the seasonal frequency of cold days (Fig. 11a) with a maximum correlation coefficient of 0.61 for the NAM index $(p<0.01)$ and a minimum correlation coefficient of 0.31 for the PCT index $(p<$ 0.1 , whereas there are no statistically significant correlation between the seasonal frequency of strong polar vortex states based on the NAM and PC1u index with the seasonal frequency of cold days. The seasonal frequency of strong polar vortex states based on PCT index negatively correlates with the seasonal frequency of cold days with a correlation coefficient of $-0.22(p<0.1)$.

In the analysis of section 3, we have found that the long-lasting weak stratospheric polar vortex signals tend to lead to long duration of CAOs. Previous studies also found that the long-lasting extreme stratospheric polar vortex events tend to have a more persistent impact on the tropospheric weather (Gerber et al. 2009; Hitchcock et al. 2013; Maycock and Hitchcock 2015; Runde et al. 2016); we therefore analyze the relationship between the duration of extreme polar vortex events and the duration of CAOs on interannual time scales. The results indicate that the persistence of weak polar vortex events positively correlates with the duration of Eurasian CAOs on interannual time scales with a maximum correlation coefficient of $0.45(p<0.01)$ for the NAM index. Note that there are fewer winters with the occurrence of Eurasian CAOs corresponding to the winters with a strong polar vortex state. Therefore there are no statistically significant correlations between the persistence of strong polar vortex events inferred from the NAM and PCT index and the duration of Eurasian CAOs. However, the correlation is statistically significant when the persistence of strong polar vortex events is inferred from the PClu index with a correlation coefficient of $-0.24(p<0.1)$.

The disagreement in the correlation between the frequency and duration of strong polar vortex states and 
(a) Frequency:cold days vs. weak vortex days

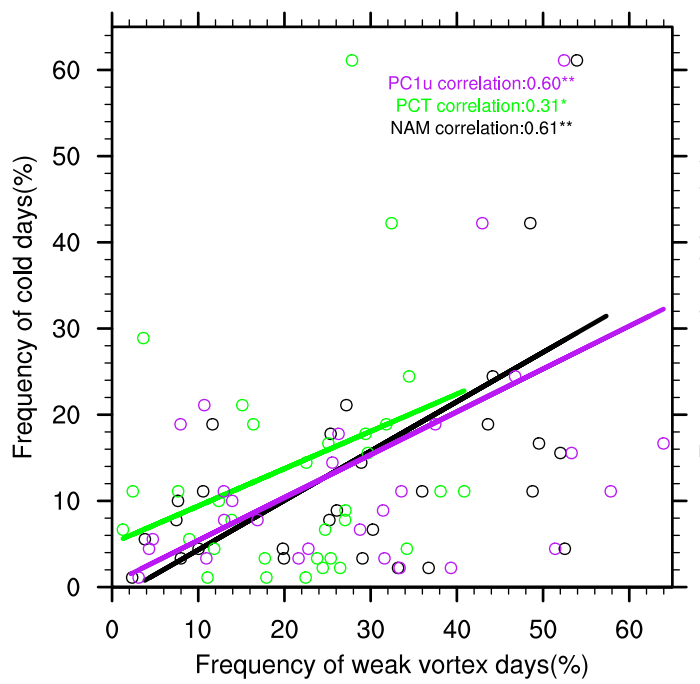

(c) Duration:CAOs vs.weak vortex events

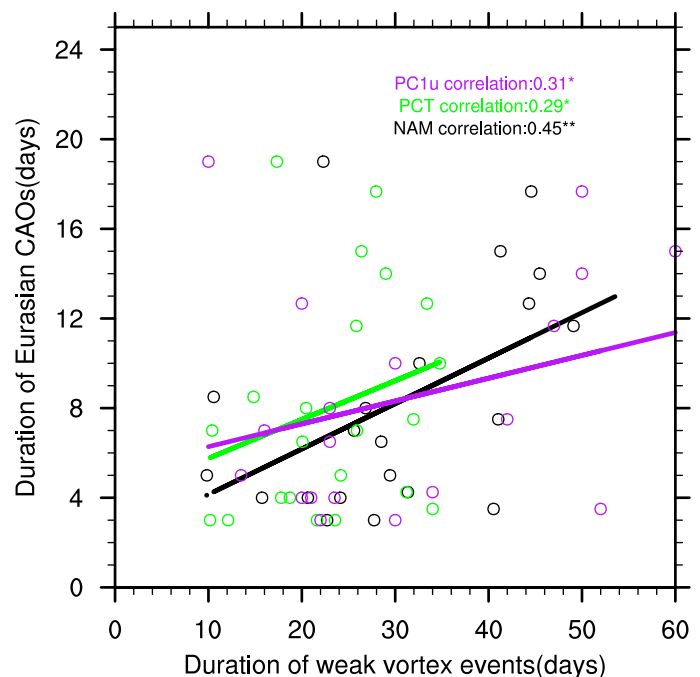

(b) Frequency:cold days vs. strong vortex days

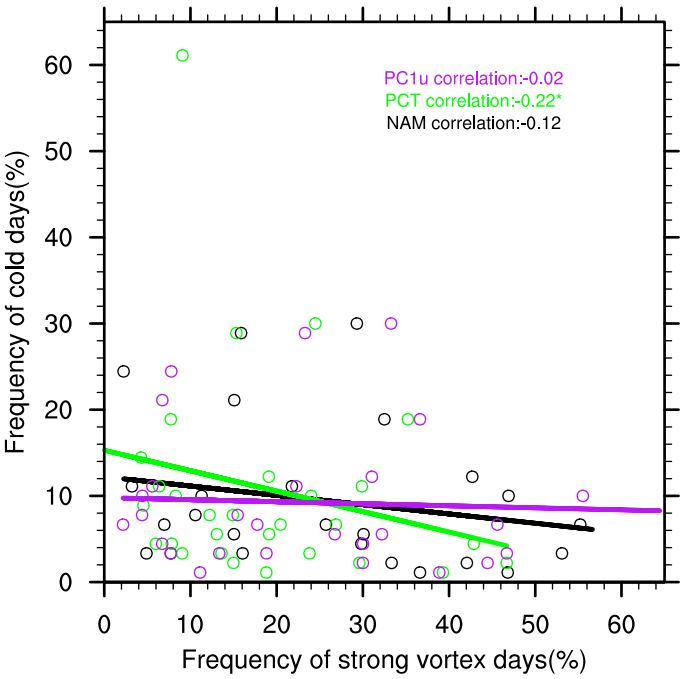

(d) Duration:CAOs vs.strong vortex events

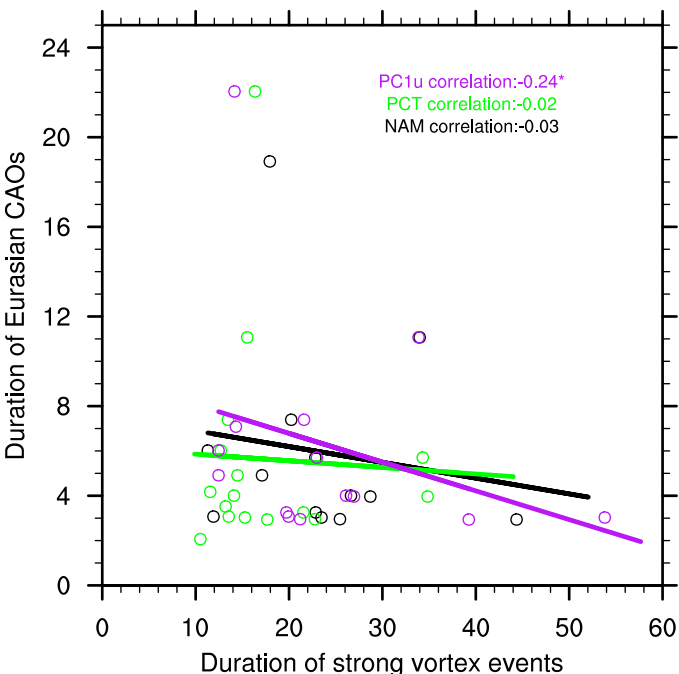

FIG. 11. (a) Scatterplots of detrended frequency of weak polar vortex days and detrended Eurasian cold days based on different polar vortex indices in JRA-55 dataset over the period 1958-2016. Black, green, and purple circles represent the NAM, PCT, and PC1u indices, respectively. (b) As in (a), but for detrended frequency of strong polar vortex days. (c),(d) As in (a) and (b), respectively, but for scatterplots of detrended duration of weak and strong polar vortex events and detrended duration of Eurasian CAOs, respectively. One asterisk (two asterisks) indicates that the correlation coefficient is statistically significant at the $90 \%(99 \%)$ confidence level.

the frequency and duration of Eurasian CAO events based on different indices is likely related to the highly variable nature of wintertime stratospheric dynamics. The identification of strong stratospheric polar vortex events is sensitive to the choice of indices. The numbers and persistence of strong polar vortex events are slightly different among different polar vortex strength indices. The number of strong polar vortex events detected by the PCT index is larger than that detected by the NAM and $\mathrm{PClu}$ index.
Figure 12 shows the time series of the frequency and duration of Eurasian cold days and the frequency and duration of the extreme stratospheric polar vortex states. The frequency of Eurasian cold days exhibit a decreasing linear trend $\left(-1.79 \%\right.$ decade $\left.^{-1}\right)$ over the period $1958-$ 2016 (Fig. 12a). The mean duration of Eurasian CAOs also shows a decreasing linear trend over this period, but the trend is not statistically significant. There are no statistically significant linear trends of the frequency and duration of weak and strong stratospheric polar 

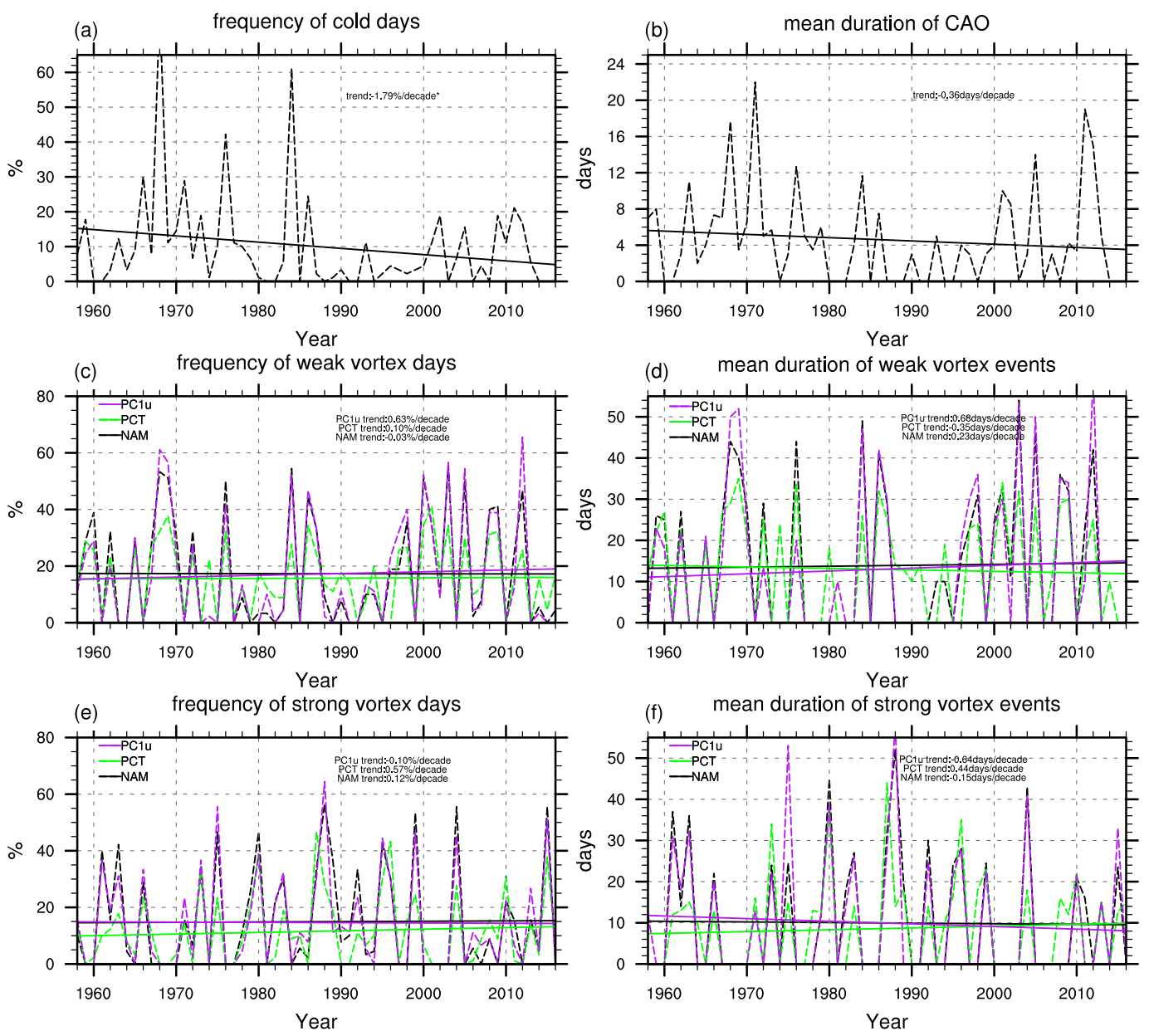

FIG. 12. (a) Time series of occurrence frequency of Eurasian cold days in winter (DJF) during the period 19582016 in the JRA-55 dataset. (b) As in (a), but for the mean duration of Eurasian CAO events. (c),(e) As in (a), but for the frequency of weak vortex days and strong vortex days, respectively. (d),(f) As in (b), but for the mean duration of weak vortex events and strong vortex events, respectively. Black, green, and purple dashed lines respectively represent three different stratospheric polar vortex strength indices. Solid lines represent the linear trends of these indices. One asterisk indicates that the linear trend value is statistically significant at the $90 \%$ confidence level.

vortex state inferred from the three types of polar vortex strength indices over the period 1958-2016.

\section{Conclusions}

Using the JRA-55 dataset, this study analyzes the differences and similarities of Eurasian cold air outbreaks (CAOs) under the conditions of weak (CAOW), strong (CAOS), and neutral (CAON) stratospheric polar vortex states. In addition, this study also examines the potential links on interannual time scales between them based on reanalysis datasets and CMIP5 simulations. The composite results indicate that the colder surface air temperature (SAT) over Europe in the earlier stages of CAOW events is likely because the amplitude of negative NAO pattern over the North Atlantic is larger in CAOW events than those in CAON and CAOS events. Marked by evidently downward extending of weak stratospheric polar vortex signals into the troposphere, the SAT over eastern Asia in CAOW events is colder than that in CAON events in the later stages of CAOs, since the negative AO phase linked to weak polar vortex lasts for a long time in CAOW events. In addition, the CAON events are colder over highlatitude regions and warmer over low-latitude regions over Eurasia than CAOS events in whole stages. This is mainly linked to the effect of negative NAO patterns in CAON events. Although anomalously strong anticyclonic flow exists in CAOW events, the differences in area-averaged SAT anomalies over northern Eurasia 
between the CAOW and CAON events are not statistically significant. This is mainly related to large-amplitude air temperature recovery caused by the larger positive diabatic heating rate anomaly associated with the larger positive sensible heat flux anomaly in CAOW events.

The analysis of Plumb fluxes indicates that except for the wave activities over the upstream blocking regions, the massive wave activities from lower latitudes over the western Pacific also play an important role in the earlier stages of these three types of CAO events. The anomalous convergences of wave fluxes over northeastern Eurasia weaken the westerly wind over this region and create favorable conditions for southward advection of cold air masses.

Statistically significant negative correlations exist between the winter-mean stratospheric polar vortex strength and the winter-mean intensity of Eurasian CAOs, and positive correlations exist between the seasonal frequency of weak polar vortex states with the seasonal frequency of Eurasian cold days, and the duration of weak polar vortex events and the duration of Eurasian CAOs. Compared to the results from the reanalysis dataset, the results from CMIP5 simulations tend to underestimate the correlation between the stratospheric polar vortex strength and the intensity of Eurasian CAOs in the historical period. The relationship between them is strengthened under RCP4.5 and RCP8.5 scenarios over the period 2006-60. In addition, the intensity of Eurasian CAOs exhibits a decreasing trend in surface observations over the period 1958-2016 and CMIP5 simulations in the historical period (1958-2005) and under both RCP4.5 and RCP8.5 scenarios (2006-60). How and to what extent natural factors (i.e., ENSO, QBO, etc.) or external forcings affect the linear trends of Eurasian CAOs in the past and in the future are worthy of further investigation but beyond the scope of this paper.

Acknowledgments. This work is supported by the National Science Foundation of China (Grants 41630421, 41705022, and 41575038). We greatly appreciate three anonymous reviewers for their constructive comments and suggestions. We thank the scientific teams at JMA, NCEP, and NCAR for providing the reanalysis data and the World Climate Research Programme's Working Group on Coupled Modelling for making CMIP5 model outputs available. We also thank the scientific teams at GHCNDEX for providing the observational climate extremes indices datasets and the groups at Canadian Centre for Climate Modelling and Analysis for providing the climate extremes indices from CMIP5 simulations.

\section{REFERENCES}

Baldwin, M. P., and T. J. Dunkerton, 2001: Stratospheric harbingers of anomalous weather regimes. Science, 294, 581-584, https://doi.org/10.1126/science.1063315.

Black, R. X., 2002: Stratospheric forcing of surface climate in the Arctic Oscillation. J. Climate, 15, 268-277, https://doi.org/ 10.1175/1520-0442(2002)015<0268:SFOSCI $>2.0$.CO;2.

_ , and B. A. McDaniel, 2004: Diagnostic case studies of the northern annular mode. J. Climate, 17, 3990-4004, https://doi.org/ 10.1175/1520-0442(2004)017<3990:DCSOTN>2.0.CO;2.

Cai, M., and R. C. Ren, 2007: Meridional and downward propagation of atmospheric circulation anomalies. Part I: Northern Hemisphere cold season variability. J. Atmos. Sci., 64, 18801901, https://doi.org/10.1175/JAS3922.1.

_ , Y. Y. Yu, Y. Deng, H. M. van den Dool, R. C. Ren, S. Saha, X. R. Wu, and J. Huang, 2016: Feeling the pulse of the stratosphere: An emerging opportunity for predicting continentalscale cold-air outbreaks 1 month in advance. Bull. Amer. Meteor. Soc., 97, 1475-1489, https://doi.org/10.1175/BAMS-D-14-00287.1.

Chen, T. C., W. R. Huang, and J. Yoon, 2004: Interannual variation of the East Asian cold surge activity. J. Climate, 17, 401-413, https://doi.org/10.1175/1520-0442(2004)017<0401:IVOTEA > 2.0.CO;2.

Cohen, J., and Coauthors, 2014: Recent Arctic amplification and extreme mid-latitude weather. Nat. Geosci., 7, 627-637, https:// doi.org/10.1038/ngeo2234.

Ding, Y. H., 1987: Monsoons Over China. Springer, 419 pp.

Donat, M., L. Alexander, H. Yang, I. Durre, R. Vose, and J. Caesar, 2013: Global land-based datasets for monitoring climatic extremes. Bull. Amer. Meteor. Soc., 94, 997-1006, https://doi.org/ 10.1175/BAMS-D-12-00109.1.

Garfinkel, C. I., S. W. Son, K. Song, V. Aquila, and L. D. Oman, 2017: Stratospheric variability contributed to and sustained the recent hiatus in Eurasian winter warming. Geophys. Res. Lett., 44, 374-382, https://doi.org/10.1002/2016GL072035.

Gerber, E. P., C. Orbe, and L. M. Polvani, 2009: Stratospheric influence on the tropospheric circulation revealed by idealized ensemble forecasts. Geophys. Res. Lett., 36, L24801, https:// doi.org/10.1029/2009GL040913.

Hitchcock, P., and I. R. Simpson, 2014: The downward influence of stratospheric sudden warmings. J. Atmos. Sci., 71, 3856-3876, https://doi.org/10.1175/JAS-D-14-0012.1.

_ T. G. Shepherd, and G. L. Manney, 2013: Statistical characterization of Arctic polar-night jet oscillation events. J. Climate, 26, 2096-2116, https://doi.org/10.1175/JCLI-D-12-00202.1.

Hoskins, B. J., M. E. McIntyre, and A. W. Robertson, 1985: On the use and significance of isentropic potential vorticity maps. Quart. J. Roy. Meteor. Soc., 111, 877-946, https://doi.org/ 10.1002/qj.49711147002.

Hu, D. Z., Z. Y. Guan, W. S. Tian, and R. C. Ren, 2018: Recent strengthening of the stratospheric Arctic vortex response to warming in the central North Pacific. Nat. Commun., 9, 1697, https://doi.org/10.1038/s41467-018-04138-3.

Huang, J. L., W. S. Tian, J. K. Zhang, Q. Huang, H. Y. Tian, and J. L. Luo, 2017: The connection between extreme stratospheric polar vortex events and tropospheric blockings. Quart. J. Roy. Meteor. Soc., 143, 1148-1164, https://doi.org/10.1002/ qj.3001.

- , L. J. Gray, J. K. Zhang, Y. Li, J. L. Luo, and H. Y. Tian, 2018: Preconditioning of Arctic stratospheric polar vortex shift events. J. Climate, 31, 5417-5436, https://doi.org/10.1175/ JCLI-D-17-0695.1. 
Ineson, S., and A. A. Scaife, 2009: The role of the stratosphere in the European climate response to El Niño. Nat. Geosci., 2, 32-36, https://doi.org/10.1038/ngeo381.

Jeong, J. H., and C. H. Ho, 2005: Changes in occurrence of cold surges over East Asia in association with Arctic Oscillation. Geophys. Res. Lett., 32, L14704, https://doi.org/10.1029/ 2005 GL023024.

, — - B.-M. Kim, and W.-T. Kwon, 2005: Influence of the Madden-Julian oscillation on wintertime surface air temperature and cold surges in East Asia. J. Geophys. Res., 110, D11104, https://doi.org/10.1029/2004JD005408.

- B. M. Kim, C. H. Ho, D. L. Chen, and G. H. Lim, 2006: Stratospheric origin of cold surge occurrence in East Asia. Geophys. Res. Lett., 33, L14710, https://doi.org/10.1029/2006GL026607.

Kalnay, E., and Coauthors, 1996: The NCEP/NCAR 40-Year Reanalysis Project. Bull. Amer. Meteor. Soc., 77, 437-471, https:// doi.org/10.1175/1520-0477(1996)077<0437:TNYRP>2.0.CO;2.

Karpechko, A. Y., P. Hitchcock, D. H. W. Peters, and A. Schneidereit, 2017: Predictability of downward propagation of major sudden stratospheric warmings. Quart. J. Roy. Meteor. Soc., 143, 14591470, https://doi.org/10.1002/qj.3017.

Kidston, J., A. A. Scaife, S. C. Hardiman, D. M. Mitchell, N. Butchart, M. P. Baldwin, and L. J. Gray, 2015: Stratospheric influence on tropospheric jet streams, storm tracks and surface weather. Nat. Geosci., 8, 433-440, https://doi.org/10.1038/ngeo2424.

Kobayashi, S., and Coauthors, 2015: The JRA-55 Reanalysis: General specifications and basic characteristics. J. Meteor. Soc. Japan, 93, 5-48, https://doi.org/10.2151/jmsj.2015-001.

Kolstad, E. W., T. Breiteig, and A. A. Scaife, 2010: The association between stratospheric weak polar vortex events and cold air outbreaks in the Northern Hemisphere. Quart. J. Roy. Meteor. Soc., 136, 886-893, https://doi.org/10.1002/qj.620.

Kretschmer, M., D. Coumou, L. Agel, M. Barlow, E. Tziperman, and J. Cohen, 2018: More-persistent weak stratospheric polar vortex states linked to cold extremes. Bull. Amer. Meteor. Soc., 99, 49-60, https://doi.org/10.1175/BAMS-D-16-0259.1.

Kuroda, Y., 2008: Effect of stratospheric sudden warming and vortex intensification on the tropospheric climate. J. Geophys. Res., 113, D15110, https://doi.org/10.1029/2007JD009550.

Lehtonen, I., and A. Y. Karpechko, 2016: Observed and modeled tropospheric cold anomalies associated with sudden stratospheric warmings. J. Geophys. Res. Atmos., 121, 1591-1610, https://doi.org/10.1002/2015JD023860.

Limpasuvan, V., D. W. J. Thompson, and D. L. Hartmann, 2004: The life cycle of the Northern Hemisphere sudden stratospheric warmings. J. Climate, 17, 2584-2596, https://doi.org/ 10.1175/1520-0442(2004)017<2584:TLCOTN $>2.0 . C O ; 2$

, D. L. Hartmann, D. W. J. Thompson, K. Jeev, and Y. L. Yung, 2005: Stratosphere-troposphere evolution during polar vortex intensification. J. Geophys. Res., 110, D24101, https:// doi.org/10.1029/2005JD006302.

Lubis, S. W., K. Matthes, N. E. Omrani, N. Harnik, and S. Wahl, 2016: Influence of the quasi-biennial oscillation and sea surface temperature variability on downward wave coupling in the Northern Hemisphere. J. Atmos. Sci., 73, 1943-1965, https://doi.org/10.1175/JAS-D-15-0072.1.

_, V. Silverman, K. Matthes, N. Harnik, N.-E. Omrani, and S. Wahl, 2017: How does downward planetary wave coupling affect polar stratospheric ozone in the Arctic winter stratosphere? Atmos. Chem. Phys., 17, 2437-2458, https://doi.org/ 10.5194/acp-17-2437-2017.

— C. S. Y. Huang, and N. Nakamura, 2018a: Role of finiteamplitude eddies and mixing in the life cycle of stratospheric sudden warmings. J. Atmos. Sci., 75, 3987-4003, https://doi.org/ 10.1175/JAS-D-18-0138.1.

,,,--- N. E. Omrani, and M. Jucker, 2018b: Role of finite-amplitude Rossby waves and nonconservative processes in downward migration of extratropical flow anomalies. J. Atmos. Sci., 75, 1385-1401, https://doi.org/10.1175/ JAS-D-17-0376.1.

Maycock, A. C., and P. Hitchcock, 2015: Do split and displacement sudden stratospheric warmings have different annular mode signatures? Geophys. Res. Lett., 42, 10 943-10 951, https://doi.org/ 10.1002/2015GL066754.

Nath, D., W. Chen, Z. L. Cai, A. I. Pogoreltsev, and K. Wei, 2016: Dynamics of 2013 sudden stratospheric warming event and its impact on cold weather over Eurasia: Role of planetary wave reflection. Sci. Rep., 6, 24174, https://doi.org/10.1038/Srep24174.

Park, T. W., C. H. Ho, S. Yang, and J. H. Jeong, 2010: Influences of Arctic Oscillation and Madden-Julian oscillation on cold surges and heavy snowfalls over Korea: A case study for the winter of 2009-2010. J. Geophys. Res., 115, D23122, https:// doi.org/10.1029/2010JD014794.

,-- , and -2011 : Relationship between the Arctic Oscillation and cold surges over East Asia. J. Climate, 24, 68-83, https://doi.org/10.1175/2010JCLI3529.1.

Perlwitz, J., and N. Harnik, 2003: Observational evidence of a stratospheric influence on the troposphere by planetary wave reflection. J. Climate, 16, 3011-3026, https://doi.org/10.1175/ 1520-0442(2003)016<3011:OEOASI $>2.0$.CO;2.

Plumb, R. A., 1985: On the three-dimensional propagation of stationary waves. J. Atmos. Sci., 42, 217-229, https://doi.org/ 10.1175/1520-0469(1985)042<0217:OTTDPO > 2.0.CO;2.

— , and K. Semeniuk, 2003: Downward migration of extratropical zonal wind anomalies. J. Geophys. Res., 108, 4223, https://doi.org/10.1029/2002JD002773.

Rayner, N. A., D. E. Parker, E. B. Horton, C. K. Folland, L. V. Alexander, D. P. Rowell, E. C. Kent, and A. Kaplan, 2003: Global analyses of sea surface temperature, sea ice, and night marine air temperature since the late nineteenth century. J. Geophys. Res., 108, 4407, https://doi.org/10.1029/2002JD002670.

Runde, T., M. Dameris, H. Garny, and D. E. Kinnison, 2016: Classification of stratospheric extreme events according to their downward propagation to the troposphere. Geophys. Res. Lett., 43, 6665-6672, https://doi.org/10.1002/2016GL069569.

Shaw, T. A., J. Perlwitz, and N. Harnik, 2010: Downward wave coupling between the stratosphere and troposphere. The importance of meridional wave guiding and comparison with zonal-mean coupling. J. Climate, 23, 6365-6381, https://doi.org/ 10.1175/2010JCLI3804.1.

Sigmond, M., J. F. Scinocca, V. V. Kharin, and T. G. Shepherd, 2013: Enhanced seasonal forecast skill following stratospheric sudden warmings. Nat. Geosci. 6, 98-102, https://doi.org/10.1038/ngeo1698.

Sillmann, J., V. V. Kharin, X. Zhang, F. W. Zwiers, and D. Bronaugh, 2013a: Climate extremes indices in the CMIP5 multimodel ensemble: Part 1. Model evaluation in the present climate. J. Geophys. Res. Atmos., 118, 1716-1733, https:// doi.org/10.1002/jgrd.50203.

— — - F. W. Zwiers, X. Zhang, and D. Bronaugh, 2013b: Climate extremes indices in the CMIP5 multimodel ensemble: Part 2. Future climate projections. J. Geophys. Res. Atmos., 118, 2473-2493, https://doi.org/10.1002/jgrd.50188.

Song, L., and R. G. Wu, 2018: Comparison of intraseasonal East Asian winter cold temperature anomalies in positive and negative phases of the Arctic Oscillation. J. Geophys. Res. Atmos., 123, 8518-8537, https://doi.org/10.1029/2018JD028343. 
Tan, B. K., L. L. Suo, and J. Y. Huang, 2008: Variability of the coupling between surface air temperature and northern annular mode at various levels (in Chinese). Acta Meteor. Sin., 22, 277-283.

Thompson, D. W. J., M. P. Baldwin, and J. M. Wallace, 2002: Stratospheric connection to Northern Hemisphere wintertime weather: Implications for prediction. J. Climate, 15, 1421-1428, https:// doi.org/10.1175/1520-0442(2002)015<1421:SCTNHW>2.0.CO;2.

Tomassini, L., E. P. Gerber, M. P. Baldwin, F. Bunzel, and M. Giorgetta, 2012: The role of stratosphere-troposphere coupling in the occurrence of extreme winter cold spells over northern Europe. J Adv. Model. Earth Syst., 4, M00A03, https:// doi.org/10.1029/2012ms000177.

Wang, L., and W. Chen, 2010: Downward Arctic Oscillation signal associated with moderate weak stratospheric polar vortex and the cold December 2009. Geophys. Res. Lett., 37, L09707, https://doi.org/10.1029/2010GL042659.

Waugh, D. W., A. H. Sobel, and L. M. Polvani, 2017: What is the polar vortex and how does it influence weather? Bull. Amer. Meteor. Soc., 98, 37-44, https://doi.org/10.1175/BAMS-D-15-00212.1.

Wen, M., S. Yang, A. Kumar, and P. Q. Zhang, 2009: An analysis of the large-scale climate anomalies associated with the snowstorms affecting China in January 2008. Mon. Wea. Rev., 137, 1111-1131, https://doi.org/10.1175/2008MWR2638.1.

Woo, S. H., B. M. Kim, and J. S. Kug, 2015: Temperature variation over East Asia during the lifecycle of weak stratospheric polar vortex. J. Climate, 28, 5857-5872, https://doi.org/10.1175/ JCLI-D-14-00790.1.

Xie, W., N. Li, C. H. Li, J. D. Wu, A. J. Hu, and X. L. Hao, 2014: Quantifying cascading effects triggered by disrupted transportation due to the great 2008 Chinese ice storm: Implications for disaster risk management. Nat. Hazards, 70, 337-352, https://doi.org/10.1007/s11069-013-0813-9.

Yu, Y. Y., M. Cai, R. C. Ren, and H. M. van den Dool, 2015a: Relationship between warm airmass transport into the upper polar atmosphere and cold air outbreaks in winter. J. Atmos. Sci., 72, 349-368, https://doi.org/10.1175/JAS-D-14-0111.1.

- R. C. Ren, and M. Cai, 2015b: Dynamic linkage between cold air outbreaks and intensity variations of the meridional mass circulation. J. Atmos. Sci., 72, 3214-3232, https://doi.org/ 10.1175/JAS-D-14-0390.1.
,-- , and $-2015 \mathrm{c}$ : Comparison of the mass circulation and $\mathrm{AO}$ indices as indicators of cold air outbreaks in northern winter. Geophys. Res. Lett., 42, 2442-2448, https://doi.org/ 10.1002/2015GL063676.

—, M. Cai, C. H. Shi, and R. C. Ren, 2018: On the linkage among strong stratospheric mass circulation, stratospheric sudden warming, and cold weather events. Mon. Wea. Rev., 146, 27172739, https://doi.org/10.1175/MWR-D-18-0110.1.

Zhang, J. K., W. S. Tian, M. P. Chipperfield, F. Xie, and J. L. Huang, 2016: Persistent shift of the Arctic polar vortex towards the Eurasian continent in recent decades. Nat. Climate Change, 6, 1094-1099, https://doi.org/10.1038/ nclimate 3136.

Zhang, R. H., W. S. Tian, J. K. Zhang, J. L. Huang, F. Xie, and M. Xu, 2019: The corresponding tropospheric environments during downward-extending and nondownward-extending events of stratospheric northern annular mode anomalies. J. Climate, 32, 1857-1873, https://doi.org/10.1175/JCLI-D-180574.1.

Zhang, Y., K. R. Sperber, and J. S. Boyle, 1997: Climatology and interannual variation of the East Asian winter monsoon: Results from the 1979-95 NCEP/NCAR reanalysis. Mon. Wea. Rev., 125, 2605-2619, https://doi.org/10.1175/1520-0493(1997)125<2605: CAIVOT $>2.0 . \mathrm{CO} ; 2$.

Zhao, L., and Coauthors, 2008: Impacts of a severe snow storm and freezing rain over southern China in January 2008 (in Chinese). Climatic Environ. Res., 13, 556-566.

Zhou, B. Z., and Coauthors, 2011: The great 2008 Chinese ice storm: Its socioeconomic-ecological impact and sustainability lessons learned. Bull. Amer. Meteor. Soc., 92, 47-60, https:// doi.org/10.1175/2010BAMS2857.1.

Zhou, W., J. C. L. Chan, W. Chen, J. Ling, J. G. Pinto, and Y. P. Shao, 2009: Synoptic-scale controls of persistent low temperature and icy weather over southern China in January 2008. Mon. Wea. Rev., 137, 3978-3991, https://doi.org/10.1175/ 2009MWR2952.1.

Zwiers, F. W., and H. von Storch, 1995: Taking serial correlation into account in tests of the mean. J. Climate, 8, 336-351, https://doi.org/10.1175/1520-0442(1995)008<0336:TSCIAI > 2.0.CO;2. 